\title{
Fibrinogen scaffolds with immunomodulatory properties promote in vivo bone regeneration
}

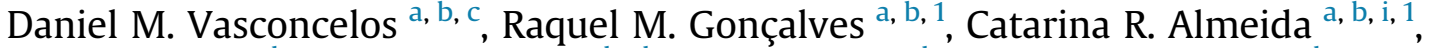 \\ Inês O. Pereira ${ }^{b}$, Marta I. Oliveira ${ }^{b, d}$, Nuno Neves ${ }^{a, b}{ }^{a}$, Andreia M. Silva ${ }^{a, b, c}$, \\ António C. Ribeiro ${ }^{\mathrm{b}}$, Carla Cunha ${ }^{\mathrm{a}, \mathrm{b}}$, Ana R. Almeida ${ }^{\mathrm{a}, \mathrm{b}, \mathrm{c}}$, Cristina C. Ribeiro ${ }^{\mathrm{a}, \mathrm{b}, \mathrm{g}}$, \\ Ana M. Gil ${ }^{\text {h}}$, Elisabeth Seebach ${ }^{\mathrm{f}}$, Katharina L. Kynast ${ }^{\mathrm{f}}$, Wiltrud Richter ${ }^{\mathrm{f}}$,

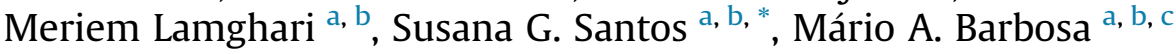

\footnotetext{
a $i 3 S$ - Instituto de Investigação e Inovação em Saúde, Universidade do Porto, Rua Alfredo Allen, 208, 4200-135 Porto, Portugal

b INEB - Instituto de Engenharia Biomédica, Universidade do Porto, Rua Alfredo Allen, 208, 4200-135 Porto, Portugal

c ICBAS-Instituto de Ciências Biomédicas Abel Salazar, Universidade do Porto, Rua de Jorge Viterbo Ferreira 228, 4050-313 Porto, Portugal

d INL- International Iberian Nanotechnology Laboratory, Braga 4715-330, Portugal

e FMUP-Faculdade de Medicina da Universidade do Porto, Departamento de Cirurgia, Serviço de Ortopedia, Alameda Prof. Hernâni Monteiro, $4200-319$ Porto, Portugal

${ }^{\mathrm{f}}$ Research Center for Experimental Orthopaedics, Department of Orthopaedics, Trauma Surgery and Paraplegiology, Heidelberg University Hospital, Schlierbacher Landstraße 200a, 69118 Heidelberg, Germany

${ }^{\mathrm{h}}$ CICECO-Aveiro Institute of Materials, Department of Chemistry, Universidade de Aveiro, Campus Universitário de Santiago, $3810-193$ Aveiro, Portugal
} \\ ${ }^{\mathrm{g}}$ Instituto Superior de Engenharia do Porto, Instituto Politécnico do Porto, Rua Dr. António Bernardino de Almeida 431, 4249-015 Porto, Portugal \\ ${ }^{i}$ Department of Medical Sciences and Institute for Biomedicine - iBiMED, University of Aveiro, 3810-193 Aveiro, Portugal
}

\section{A R T I C L E I N F O}

\section{Article history:}

Received 16 June 2016

Received in revised form

30 September 2016

Accepted 1 October 2016

Available online 4 October 2016

\section{Keywords:}

Fibrinogen

In vivo

Bone repair/regeneration

Inflammation

Biomaterial

\begin{abstract}
A B S T R A C T
The hypothesis behind this work is that fibrinogen (Fg), classically considered a pro-inflammatory protein, can promote bone repair/regeneration. Injury and biomaterial implantation naturally lead to an inflammatory response, which should be under control, but not necessarily minimized. Herein, porous scaffolds entirely constituted of Fg (Fg-3D) were implanted in a femoral rat bone defect and investigated at two important time points, addressing the bone regenerative process and the local and systemic immune responses, both crucial to elucidate the mechanisms of tissue remodelling. Fg-3D led to early infiltration of granulation tissue ( 6 days post-implantation), followed by bone defect closure, including periosteum repair ( 8 weeks post-injury). In the acute inflammatory phase (6 days) local gene expression analysis revealed significant increases of pro-inflammatory cytokines IL-6 and IL-8, when compared with non-operated animals. This correlated with modified proportions of systemic immune cell populations, namely increased T cells and decreased B, NK and NKT lymphocytes and myeloid cell, including the Mac$1+(\mathrm{CD} 18+/ \mathrm{CD} 11 \mathrm{~b}+)$ subpopulation. At 8 weeks, Fg-3D led to decreased plasma levels of IL-1 $\beta$ and increased TGF- $\beta 1$. Thus, our data supports the hypothesis, establishing a link between bone repair induced by Fg-3D and the immune response. In this sense, Fg-3D scaffolds may be considered immunomodulatory biomaterials.
\end{abstract}

(C) 2016 Elsevier Ltd. All rights reserved.

\section{Introduction}

Upon injury and/or biomaterial implantation there is an

\footnotetext{
* Corresponding author. i3S - Instituto de Investigação e Inovação em Saúde, Universidade do Porto, Rua Alfredo Allen, 208, 4200-135 Porto, Portugal.

E-mail address: susana.santos@ineb.up.pt (S.G. Santos).

${ }^{1}$ These authors contributed equally to this work.
}

inflammatory response, which is required for the regenerative process to begin. This inflammatory response to implantable, and particularly non-degradable biomaterials, can culminate in a foreign body reaction, which is related with the failure to establish a pro-regenerative environment [1]. First generations of materials applied in clinics aimed at restoration of the physical properties of the damaged tissues, while minimizing or even avoiding the immune response. Most of the currently used dental and orthopaedic 
implants are examples of biomaterials that still follow that strategy [2]. However, in terms of biomedical research the paradigm is shifting from "fighting inflammation" to "modulating inflammation" [3].

Inflammation, repair and remodelling are the three stages that compose bone healing [4]. First, a blood clot forms after bone injury, which provides a temporary matrix for immune cell recruitment to the injury site. Polymorphonuclear leukocytes (PMN) quickly migrate to bone injury and interact with damaged tissue during the first $24 \mathrm{~h}$. Monocytes/Macrophages and lymphocytes (NK, T and B cells) are attracted to the injury in the next days [5]. Although acute inflammation is described as lasting 4 days and the chronic inflammation to be over in about 2 weeks, immune cells have an active role throughout bone repair and remodelling $[4,5]$. In fact, the balance between cytokines, chemokines and immune cell populations in the injury microenvironment is essential for tissue regeneration. This can be impaired by infection or chronic inflammatory conditions, such as autoimmune diseases and the foreign body response against a biomaterial, and when inflammation does not resolve and tissue healing is impaired $[4,6]$. In agreement, previous work has shown that successful osteointegration of implants correlates with systemic changes in immune cells [7].

Fibrinogen $(\mathrm{Fg})$ is a blood protein involved in blood clotting. During haemorrhage, a fibrin clot is formed from Fg cleaved by thrombin, which prevents extensive blood loss. The Fg-derived clot is the primordial extracellular matrix (ECM) that supports tissue regeneration, thus providing $\mathrm{Fg}$ with pro-healing properties $[8,9]$. Two arginine-glycine-aspartate (RGD) motifs were identified in Fg structure [10], which are related with improved cell adhesion to Fgmodified materials [11]. Additionally, Mac-1, an important receptor of activated immune cells, finds numerous binding sites on the Fg molecule [12]. Also, vascular endothelial growth factor (VEGF), an important factor for neovascularization, binds Fg with high affinity [13], what may explain the improved angiogenesis induced by Fg $[7,14]$.

Clinically, fibrinogen is applied together with thrombin as fibrin hydrogels that are used as biological adhesives [15]. Beyond their well-known haemostatic and sealant properties, alternative applications in tissue engineering have been tested, combining fibrin with ceramics, cells or other proteins [16-20]. Although the use of thrombin is a standard in fibrin sealants, it increases the risk of thrombosis and life-threatening complications.

The strategy of Fg delivery appears to be of paramount importance to the host response. Soluble Fg does not enhance wound healing [11], instead elicits autoimmunity and nervous tissue damage [21]. The pro-regenerative potential of Fg-incorporating biomaterials has been previously reported by us [7] and others [22]. We have explored the potential of adsorbed Fg to modulate immune cell responses and induce regeneration. Materials modified with Fg led to increased recruitment of mesenchymal stem/ stromal cells (MSC) mediated by different immune cells [23], downregulation of pro-inflammatory molecules and up-regulation of bone and angiogenic factors secreted by macrophages [24]. The degradation of chitosan films by osteoclasts was also accelerated by Fg adsorption [25]. Most importantly, our previous work showed that implantation of Fg-modified chitosan scaffolds in a femoral critical bone defect led to increased angiogenesis and new bone formation at the defect periphery, together with significant changes in myeloid and B cell populations in the draining lymph nodes [7].

Due to the potential revealed by Fg-modified materials [7,23,24], whole-Fg scaffolds (Fg-3D) were here produced to assess the hypothesis that, when stabilized in a 3D porous structure, Fg can promote a pro-regenerative microenvironment, mimicking the blood clot. Fg-3D scaffolds were produced by freeze drying, without addition of any exogenous enzymatic compound, and their capacity to stimulate bone repair was addressed. For that, Fg-3D were extensively characterized by SEM, ATR-FTIR and NMR, their degradation profile, cytotoxicity and endotoxin levels were assessed, following the international standard ISO 10993-5:2009. Fg-3D scaffolds were then implanted in a load-bearing bone defect in the rat femur. Local and systemic immune responses were analysed at two critical time points post-implantation, 6 days and 8 weeks. A combination of flow cytometry and ELISA was used to investigate the systemic response, while qRT-PCR complemented the histological analysis of the local response. Bone repair was also more closely evaluated by micro-CT. By assessing the early and long-term biological response we aim at understanding the impact of Fg-3D on the inflammatory response and subsequent influence on bone tissue repair (Fig. 1).

\section{Materials and methods}

\subsection{Preparation of Fg-3D scaffolds}

Fibrinogen 3D scaffolds (Fg-3D) were prepared by freeze-drying, similarly to chitosan scaffolds previously prepared by our group [7]. A solution of human $\mathrm{Fg}$ (fraction I, type III from human plasma; cat. F4129, Sigma), $70 \mathrm{mg} / \mathrm{mL}$, was prepared in Phosphate Buffered Saline Solution (PBS) at neutral pH (7.4). The solution was then casted into 48 -well plate $(800 \mu \mathrm{L} /$ well $)$, frozen overnight at $-20^{\circ} \mathrm{C}$ in a horizontal surface and freeze-dried at $-80^{\circ} \mathrm{C}$ for $48 \mathrm{~h}$ to produce scaffolds. These were removed from the plate and cut in the shape of cylinders with $4 \mathrm{~mm}$ diameter and $5 \mathrm{~mm}$ height. Scaffolds were neutralized and disinfected through impregnation under vacuum in a gradient of ethanol solutions $(99.9 \%$, for $10 \mathrm{~min}, 70 \%$ for $30 \mathrm{~min}, 50 \%$ and $25 \%$ for $10 \mathrm{~min}$ each), followed by three $10 \mathrm{~min}$ washes in sterile PBS. Fg-3D scaffolds were maintained overnight in sterile PBS at $4{ }^{\circ} \mathrm{C}$ protected from light, before further analysis or implantation.

\subsection{Scanning electron microscopy characterization}

Cross-sections of $1 \mathrm{~mm}$ thickness were cut and mounted with carbon tape, for scanning electron microscopy (SEM) analysis. Samples were sputter-coated with gold and observed with a JEOL JSM-6301F SEM, at $15 \mathrm{kV}$ and magnifications of $30 \times$ or $250 \times$. Twenty-five pores and interconnecting pores were measured in a representative scaffold to determine the range of pore sizes.

\subsection{ATR-FTIR spectroscopy}

Previously to FTIR analysis, all samples were dried in a vacuum chamber overnight at room temperature. ATR-FTIR spectra of Fg powder, lyophilized Fg scaffolds and after ethanol neutralization (Fg-3D) were obtained using a FTIR spectrophotometer (SpectrumTwo, Perkin Elmer). All samples were submitted to the same pressure and 16 scans were collected with $4 \mathrm{~cm}^{-1}$ resolution. Peak analysis was performed through spectra analysis and evaluation of first and second derivatives.

\subsection{NMR analysis}

The ${ }^{13} \mathrm{C}$ NMR spectra were recorded using a Bruker Avance III (9.4 T) spectrometer operating at $400 \mathrm{MHz}$ for proton and a $4-\mathrm{mm}$ double-bearing magic-angle spinning (MAS) probe. For the ${ }^{13} \mathrm{C}$ cross-polarization and MAS (CP-MAS) NMR experiments, we used $90^{\circ}$ pulse lengths of $3-5 \mu \mathrm{s}$, a 2 ms contact time, a 5 s recycle delay and a spinning rate of $12 \mathrm{kHz}$. For the ${ }^{13} \mathrm{C}$ Single Pulse Excitation 


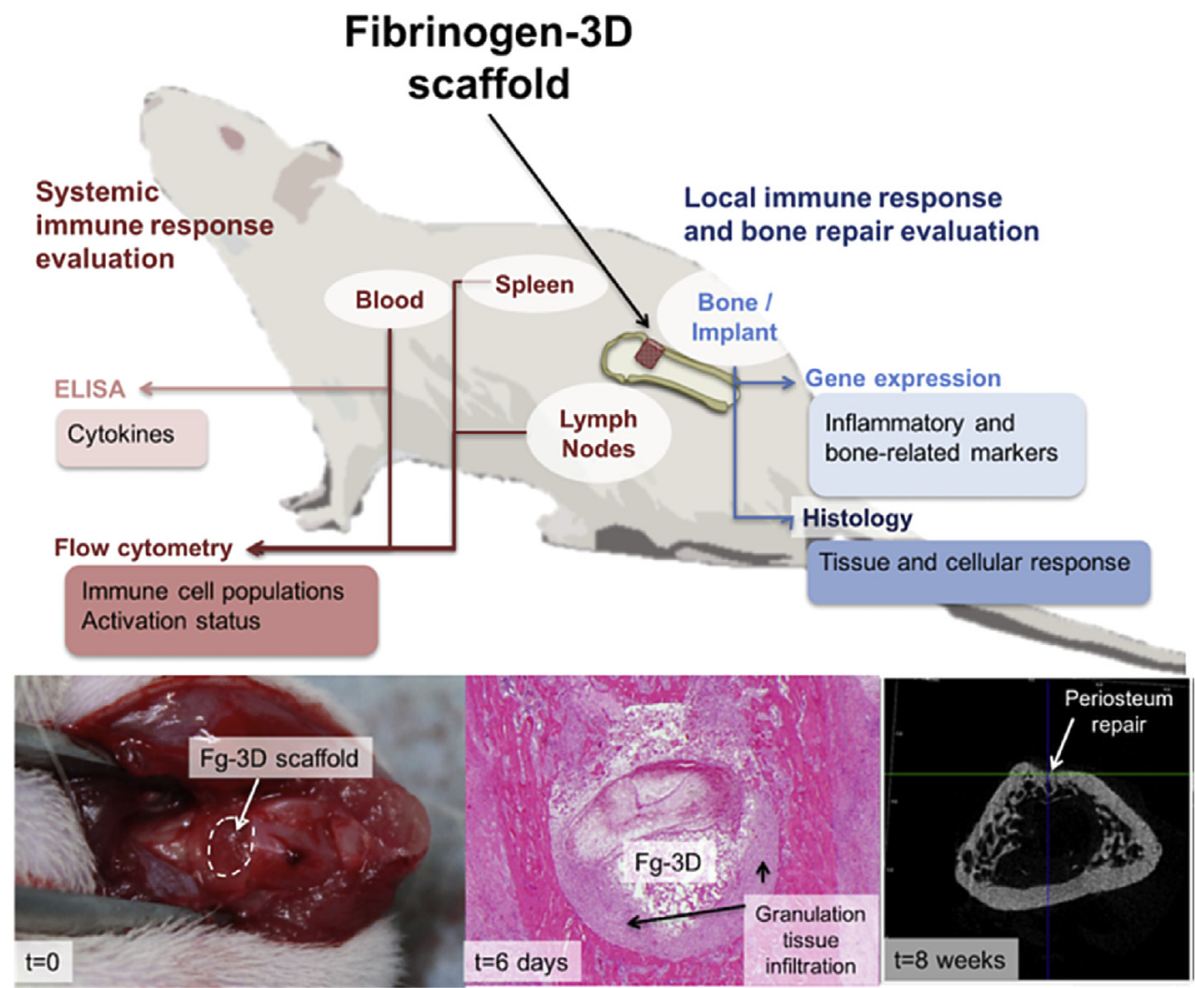

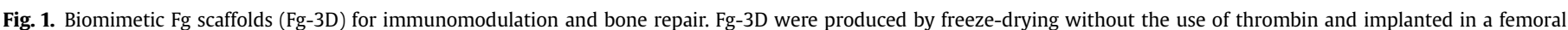

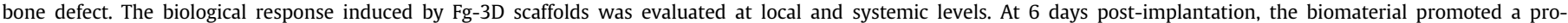

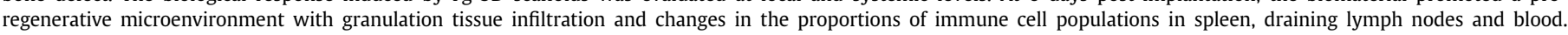
Interestingly, bone defect, including periosteum, was repaired in the animals with Fg-3D, 8 weeks upon injury.

(SPE) spectra, $90^{\circ}$ pulse lengths of $4-5 \mu \mathrm{s}$, a 20 s recycle delay and a spinning rate of $12 \mathrm{kHz}$ were employed.

\subsection{Measuring endotoxin levels}

Extracts were prepared from $35 \mathrm{mg}$ of Fg-3D scaffolds in $1.4 \mathrm{~mL}$ of endotoxin-free water ( $40 \mathrm{~mL}$ per $\mathrm{g}$ of material) by continuous shaking $(250 \mathrm{rpm})$ at $50{ }^{\circ} \mathrm{C}$ for $24 \mathrm{~h}$. Endotoxin levels were assessed using the Food and Drug Administration (FDA, USA) approved Endosafe $^{\mathrm{TM}}$-PTS system (Charles River, USA). The analysis was performed and certified by an external entity (Analytical Services Unit, IBET/ITQB, Oeiras, Portugal). Extracts from Fg-3D scaffolds revealed endotoxin levels of $0.132 \mathrm{EU} / \mathrm{mL}$ (EU: unit of measurement for endotoxin activity), which are far below the recommended FDA limit $(0.500 \mathrm{EU} / \mathrm{mL})$.

\subsection{Degradation assay}

Fg-3D were incubated at $37{ }^{\circ} \mathrm{C}$ with distilled water or heatinactivated fetal bovine serum (FBS) to evaluate hydrolysis and proteolysis at $0.1 \mathrm{mg}$ of scaffold to $1 \mathrm{~mL}$ of fluid according to ISO 10993-5:2009 standard. Supernatants were discarded after 6, 24, 48 and $100 \mathrm{~h}$ of incubation and remaining scaffolds were freezedried and weighted.

\subsection{Evaluation of cytotoxicity}

The cytotoxicity of Fg-3D was assessed using the MC3T3 cell line according to the guidelines presented in ISO 10993-5:2009 standard. In detail, MC3T3 cells were seeded in a 96-well plate at a final density of 10,000 cells per well in supplemented minimum essential medium eagle-alpha modification ( $\alpha$-MEM, with $10 \% \mathrm{v} / \mathrm{v}$ FBS and $1 \% \mathrm{v} / \mathrm{v}$ penicillin/streptomycin) and allowed to adhere for $24 \mathrm{~h}$ at $37{ }^{\circ} \mathrm{C}$. Afterwards, the medium was removed and the experimental conditions were set: control (only basal medium), direct contact (in presence of Fg-3D) and four conditions using 100, 75,50 and $25 \%$ of Fg extract complemented with $\alpha$-MEM without FBS. Extracts were produced by incubating Fg-3D in $\alpha$-MEM at $100 \mathrm{mg} / \mathrm{mL}$ under agitation (100 rpm), for $24 \mathrm{~h}$ at $37^{\circ} \mathrm{C}$. After $24 \mathrm{~h}$ the medium and the scaffolds were removed and $300 \mu \mathrm{L}$ of $10 \%$ resazurin solution in basal medium was added. Supernatants were transferred to a black 96 -well plate $3 \mathrm{~h}$ after incubation at $37^{\circ} \mathrm{C}$ and fluorescence was read (excitation $\lambda=530 \mathrm{~nm}$, emission $\lambda=590 \mathrm{~nm}$ ). Experiments were done in triplicate and data were normalized by the control. Conditions that lead to a percentage of metabolic activity bellow $70 \%$ of the control were considered cytotoxic.

\subsection{Animal model}

All animal experiments were conducted following protocols approved by the Ethics Committee of the Portuguese Official Authority on Animal Welfare and Experimentation (DGV). We have used a critical size bone defect model, adapted from the study of Le Guehennec L et al. [26], and previously used by our team [7]. Briefly, three months old male Wistar rats ( $\mathrm{n}=17$ per group, 12 for analysis after 6 days, and 5 after 8 weeks) were operated under general anaesthesia performed by inhalation of isoflurane. The knees were shaved and disinfected. An incision was made in the skin, and both skin and muscle were retracted. After lateral knee arthrotomy, a cylindrical defect with $3 \mathrm{~mm}$ diameter and depth of approximately $4 \mathrm{~mm}$ was created using a surgical drill in the anterior wall of the 
lateral condyle of the right femur. Animal care and analgesics (subcutaneous injection of Buprex-buprenorphine, $0.05 \mathrm{mg} / \mathrm{kg}$ ) were provided during post-surgery. Surgery was performed in only one femur per animal and defects either received Fg-3D or remained empty. Non-operated animals were used as control.

\subsection{Blood, spleen and lymph nodes collection}

The number and type of biological samples collected at 6 days and 8 weeks post-implantation as well as the methods applied in their analysis are summarized in Fig. S1. Twelve animals per group were sacrificed 6 days post-injury while five were euthanized at 8 weeks. Unfortunately, three animals from the empty group at 6 days were excluded from the analysis, two due to infection and one due to non-standard defect size. For tissue collection and euthanasia, animals were anesthetized and kept under general anaesthesia by inhalation of isoflurane. Blood was collected by intracardiac puncture and placed in a tube containing heparin solution (B. Braun) at a 1:10 dilution, to avoid blood coagulation. Animals were then dissected and the spleen, as well as the inguinal and popliteal lymph nodes on the side of injury, were collected into a tube with $2 \mathrm{~mL}$ of RPMI supplemented with $10 \%$ FBS to maintain cell viability until processing.

\subsection{Bone collection}

Immediately after organs collection, the muscle tissue around the defect region was carefully removed and femurs were retrieved. At 6 days, 7 out of 12 femurs per group were prepared for gene expression analysis. Briefly, the femur to be analysed was placed in a Teflon holder and a cylindrical sample including the bone defect with or without Fg-3D and peripheral bone tissue was cut using a $5 \mathrm{~mm}$ diameter driller. Bone cylinders were transferred to $1.5 \mathrm{~mL}$ tubes and gently swirled in liquid nitrogen until completely frozen. Samples were maintained at $-80{ }^{\circ} \mathrm{C}$ until RNA extraction. The remaining five femurs were collected for histological analysis at day 6 and 8 weeks upon injury.

\subsection{Bone histological analysis}

Femurs were retrieved, fixed, decalcified, dehydrated and defatted before embedding in paraffin, as previously described $[7,27,28]$, in five animals per group. Sagittal tissue sections, $3 \mu \mathrm{m}$ thick, were mounted on pre-coated poly-L-lysine glass slides and dried overnight at $37^{\circ} \mathrm{C}$. Prior to the different staining procedures, the sections were first deparaffinized in xylol $(3 \times 5 \mathrm{~min})$ and rehydrated through a decreasing ethanol series $(2 \times 100 \%$ ethanol, $96 \%$ ethanol, $70 \%$ ethanol, $50 \%$ ethanol, distilled water, 3 min each). Contiguous sections were stained with haematoxylin \& eosin (H\&E) and Masson's trichrome (MT) at three depths, and analysed using a light microscope Olympus CX31 for both studied timepoints. Images were acquired with Olympus DP 25 camera, using the Cell B software.

The inflammatory response was evaluated at day 6 , namely the presence of PMN and the infiltration of granulation tissue in the vicinity of the bone defect. Tartrate resistant acid phosphatase (TRAP) assay (Sigma-Aldrich) was performed according to the manufacturer's instructions. After rehydration, slices were immersed in a staining solution containing water, acetate, naphthol and one capsule of fast garnet GBC salt for $1 \mathrm{~h}$ at $37{ }^{\circ} \mathrm{C}$ in the dark, and counterstained with acid haematoxylin solution. For alkaline phosphatase (ALP) staining slices were incubated in a Naphthol ASMX phosphate solution containing the Fast Violet B salt (both from Sigma) for $30 \mathrm{~min}$ at $37^{\circ} \mathrm{C}$.

\subsection{Micro-computed tomography (micro-CT)}

New bone formation was evaluated 8 weeks post-injury using a high-resolution micro-CT Sky-Scan 1072 (Skyscan, Belgium) at 3B's Services and Consulting (Caldas das Taipas, Portugal). Images were acquired using a pixel size of $17.58 \mu \mathrm{m}$ and an exposure time of $8550 \mathrm{~ms}$. The X-ray source was set at $80 \mathrm{kV}$ and $104 \mu \mathrm{A}$. Approximately 400 projections were acquired over a rotation range of $180^{\circ}$, with a rotation step of $0.45^{\circ}$. Datasets were reconstructed using standardized cone-beam reconstruction software NRecon ${ }^{\circledR}$ and $\mathrm{CTvox}^{\circledR}$ software (SkyScan, Belgium). The amount of calcified tissue was quantified in cylindrical volume of interest (VOI) with $3 \mathrm{~mm}$ in diameter and 114 slices in deepness $(2 \mathrm{~mm})$. The VOI was centred with the defect region (Fig. S2), and bone parameters were quantified using $C \operatorname{Tan}^{\circledR}$ software (Skyscan, Belgium). Threshold was set at 70 to define calcified tissue. The mean grayscale within the VOI was determined to evaluate bone density. Changes in bone architecture were assessed in the VOI by 3D analysis of bone volume/ tissue volume $(\mathrm{BV} / \mathrm{TV})$, trabecular number $(\mathrm{Tb} \cdot \mathrm{N})$, trabecular thickness $(\mathrm{Tb} \cdot \mathrm{Th})$ and trabecular separation $(\mathrm{Tb} \cdot \mathrm{Sp})$. Parameters are shown following ASBMR nomenclature [29].

\subsection{Local $q R T-P C R$ analysis}

Local gene expression of pro-inflammatory cytokines and growth factors at the defect/implant site was analysed in 7 animals for each condition 6 days upon injury. $\mathrm{N}_{2}$ shock-frozen bone cylinders were pulverized using a micro-dismembrator (B Braun Biotech, Germany) at $3000 \mathrm{rpm}$ for $2 \mathrm{~min}$ and total RNA was extracted using Mirvana RNA extraction kit (Invitrogen) immediately after. RNA was quantified by Nanodrop ND-1000 (Thermo Fisher Scientific). cDNA was obtained from $1 \mu \mathrm{g}$ of total RNA with oligo (dT) primers (Qiagen) using Superscript II kit (Invitrogen) according to manufacturer instructions. All used primers, listed in Supplementary Table 1, were designed using Primer 3 software to be inter-exonic and were obtained from Eurofins Genomics (Ebersberg, Germany). Primer pairs for IL-1 $\beta$, IL-2, IL-6, IL-8 (MIP2 ), IL-10, OC, TNF- $\alpha$ and VEGF evaluation were designed and used previously [18]. Quantitative real time PCR (qRT-PCR) reactions containing $12.5 \mu \mathrm{L}$ of SYBR Green PCR Mastermix (Thermo), $2 \mu \mathrm{L}$ of 5 times diluted cDNA template, $0.5 \mu \mathrm{L}$ of forward and reverse primers $(100 \mathrm{pmol} / \mu \mathrm{L})$ and $9.5 \mu \mathrm{L}$ of RNAse free water were carried out on a LightCycler 96 (Roche). The reactions were pre-incubated for $10 \mathrm{~min}$ at $95^{\circ} \mathrm{C}$, followed by 40 thermal cycles of amplification (95 ${ }^{\circ} \mathrm{C}$ for $15 \mathrm{~s} ; 58^{\circ} \mathrm{C}$ for $10 \mathrm{~s} ; 72{ }^{\circ} \mathrm{C}$ for $30 \mathrm{~s}$ ), ending with a melting cycle $95{ }^{\circ} \mathrm{C}$ for $30 \mathrm{~s} ; 58{ }^{\circ} \mathrm{C}$ for $60 \mathrm{~s} ; 95{ }^{\circ} \mathrm{C}$ for $1 \mathrm{~s}$. Relative gene expression was calculated using the $2^{-\Delta \mathrm{Ct}}$ method and normalized using GAPDH as reference gene.

\subsection{Tissue processing and flow cytometry}

Peripheral blood mononuclear cells were isolated from blood by density centrifugation over Lymphoprep (Axis-Shield) at $800 \mathrm{~g}$, for 30 min without brake, at room temperature. Plasma was collected, spun to remove cell debris and kept at $-80^{\circ} \mathrm{C}$ until further analysis. Cells were collected from the interface between plasma and Lymphoprep and washed twice with PBS. Lymph node cells were obtained by placing lymph nodes on top of a $100 \mu \mathrm{m}$ pore cell strainer and gently crushing with the end of a syringe piston. The strainer was then washed with PBS. To collect cells from the spleen, half of this organ was injected with $100 \mathrm{U} / \mathrm{ml}$ Collagenase I (Sigma) and gently crushed with the top of a syringe piston on the top of a $100 \mu \mathrm{m}$ pore cell strainer. The strainer was then washed with PBS and red blood cells (RBC) were lysed with $\mathrm{RBC}$ lysis buffer $(10 \mathrm{mM}$ Tris, $150 \mathrm{mM} \mathrm{NH}{ }_{4} \mathrm{Cl}, \mathrm{pH} 7.4$ ) for $8 \mathrm{~min}$ at $37^{\circ} \mathrm{C}$. The cells obtained 
from each tissue were washed with PBS and transferred to 96-well U-bottom plates. Cells were incubated for $5 \mathrm{~min}$ on ice with $1 \mu \mathrm{l}$ per sample of Mouse Anti-Rat CD32 (Fcyll Receptor) Monoclonal Antibody (BD), diluted in PBS, $0.5 \%$ BSA, $0.01 \%$ sodium azide, to prevent unspecific binding to Fc receptors. Cell surface staining for flow cytometry was then performed by incubating for 30 min on ice with the following antibodies diluted in PBS, 0.5\% BSA, 0.01\% sodium azide: anti-rat CD45R-PE (clone HIS24, $4 \mu \mathrm{g} / \mathrm{mL}$ ), anti-rat TCRPerCP (clone R73, $2 \mu \mathrm{g} / \mathrm{mL}$ ), anti-rat CD4-APC (clone OX35, $2 \mu \mathrm{g}$ / $\mathrm{mL}$ ), anti-rat CD4-V450 (clone OX-35, $4 \mu \mathrm{g} / \mathrm{mL}$ ), anti-rat CD8-V450 (clone OX-8, $4 \mu \mathrm{g} / \mathrm{mL}$ ), anti-rat CD18-FITC (clone WT.3, $2 \mu \mathrm{g} / \mathrm{mL}$ ), anti-rat CD161a-FITC (clone 10/78, $2 \mu \mathrm{g} / \mathrm{mL}$ ), anti-rat MHC class IIAlexaFluor 647 (clone OX-6, $2 \mu \mathrm{g} / \mathrm{mL}$ ) and anti-rat CD11b/c-PE-Cy7 (clone OX-42, $4 \mu \mathrm{g} / \mathrm{mL}$ ), all from BD. Cells were also stained with the corresponding isotype controls. Samples were then washed 4 times in PBS, followed by fixation in paraformaldehyde 4\%, $20 \mathrm{~min}$ on ice, and washed twice with PBS. Samples were acquired on a Flow Cytometer (FACSCanto, Becton Dickinson) and data was analysed with FlowJo software. Only samples resulting in more than 10,000 gated events were considered for further analysis.

\subsection{Cytokine production}

For cytokine evaluation, plasma from each animal was assayed by ELISA specific for TNF- $\alpha$, IL-6, IL-17A and TGF- $\beta 1$ (Legend Max Rat ELISA kits, BioLegend, CA, USA) and IL-1 $\beta$ (Rat IL-1 $\beta$ Mini ABTS ELISA Development Kit, Peprotech, NJ, USA) according to the manufacturer's protocol. Cytokine concentration was calculated against a standard curve.

\subsection{Statistical analysis}

Statistical analysis was performed using Prism software. Visual histogram analysis and Kolmogorov-Smirnov test were used to evaluate the normal distribution of the studied variables (all continuous). To compare data from two different groups, MannWhitney $U$ test (or its parametric counterpart Student's t-test) were used. When comparing three different groups, Kruskal-Wallis followed by Dunn's Multiple Comparison test (or their parametric counterpart ANOVA) were used. Statistical significance was considered for $\mathrm{p}<0.05\left(^{*}\right)\left({ }^{* *}: \mathrm{p}<0.01,{ }^{* * *}: \mathrm{p}<0.001\right)$.

\section{Results}

To test our hypothesis that fibrinogen (Fg) can promote bone repair/regeneration when stabilized as a 3D structure, Fg-3D scaffolds were produced, characterized and implanted in a rat femoral defect. Bone regeneration/repair was evaluated at 6 days (acute phase of inflammation) and 8 weeks (repair of bone defect) postinjury, together with the local and systemic immune responses.

\subsection{Production and characterization of Fg-3D scaffolds}

Fg scaffolds were produced using freeze-drying methodologies, as previously described for other materials [7]. The influence of the major steps involved in the preparation of Fg-3D (lyophilization and ethanol neutralization) on the protein structure was characterized by ATR-FTIR spectroscopy and solid state ${ }^{13} \mathrm{C}$ NMR spectroscopy (Fig. 2).

Fg secondary structures are known to comprise segments in $\alpha$ helix, $\beta$-sheet, $\beta$-turn and random coils, which can be evaluated through the IR spectra fingerprint region $\left(1800-1000 \mathrm{~cm}^{-1}\right)$, namely the Amide I (1700-1600 $\left.\mathrm{cm}^{-1}\right)$ and Amide II $\left(1600-1500 \mathrm{~cm}^{-1}\right)$ band regions [30,31]. ATR-FTIR analysis of Fg powder showed bands at $1644 \mathrm{~cm}^{-1}$ (random coil), $1548 \mathrm{~cm}^{-1}(\alpha-$ helix), $1532 \mathrm{~cm}^{-1}$ ( $\beta$-sheet), $1516 \mathrm{~cm}^{-1}$ (tyrosine side chains), $1398 \mathrm{~cm}^{-1}\left(\mathrm{COO}^{-}\right.$symmetric stretching band and/or the deformation of $\mathrm{CH}_{2}$ and $\mathrm{CH}_{3}$ ) and $1078 \mathrm{~cm}^{-1}(\mathrm{C}-\mathrm{O}$ stretching modes of glycoprotein in the Fg structure) (Fig. 2A). Lyophilized Fg scaffold presented a relative increase of the peak at $1591 \mathrm{~cm}^{-1}$ (compression carboxylate side chains of amino acids) and at $1610 \mathrm{~cm}^{-1}$ ( $\beta$-sheet aggregates structure) together with changes in 1235-1270 band region, which are related with the $\mathrm{C}-\mathrm{N}$ stretching in Amide III region. The spectrum obtained for the neutralized Fg scaffold (Fg-3D) was broadly similar to that obtained for Fg powder. Moreover, the hydration water of Fg was not modified by the production of Fg-3D, as no significant changes of the ratios between Amides and hydrogen bonds (Amide I/ $3280 \mathrm{~cm}^{-1}$ and Amide $\mathrm{II} / 3280 \mathrm{~cm}^{-1}$ ratios) were observed. Remarkably, a relevant decrease of intensity of peaks at $1398 \mathrm{~cm}^{-1}$ and $1591 \mathrm{~cm}^{-1}$ were registered in Fg-3D.

Human $\mathrm{Fg}$ is a dimeric glycoprotein composed of three pairs of peptide chains, where all 20 amino acids are present, and the corresponding ${ }^{13} \mathrm{C}$ CP-MAS spectrum showed a typical protein profile (Fig. 2B). Some spectral changes were noted between lyophilized Fg scaffolds and Fg-3D. Upon scaffold neutralization, the ${ }^{13} \mathrm{C} C \mathrm{CP}-\mathrm{MAS}$ spectrum revealed a profile with increased resolution, indicating that there is increased molecular organization in the rigid domains of the protein for Fg-3D. Concomitantly, the ${ }^{13} \mathrm{C}$ SPE spectrum also showed better resolved resonances in the neutralized Fg samples, which points towards increased molecular mobility of the more mobile protein domains. Moreover, a peak clearly observed at $76 \mathrm{ppm}$ in the CP-MAS spectrum of the lyophilized Fg scaffolds, was no longer observed upon neutralization.

\subsection{Fg-3D scaffolds have interconnected porosity, are degradable and non-cytotoxic}

To determine their structure and porosity, Fg-3D scaffolds were observed using scanning electron microscopy (SEM), and after haematoxylin-eosin (H\&E) staining by light microscopy (Fig. S3). Overall, Fg scaffolds presented a uniform porous network with macroporosity ranging from 104 to $165 \mu \mathrm{m}$ in diameter and interconnecting micropores varying in diameter between 17 and $57 \mu \mathrm{m}$ (Fig. $3 \mathrm{~A}$ and $\mathrm{B}$ ).

Then, the susceptibility of Fg-3D to hydrolysis and proteolysis was evaluated through incubation at $37^{\circ} \mathrm{C}$ for up to 4 days in water and in serum (FBS) (Fig. 3C). Fg-3D showed a fast degradation rate in water ( $82 \%$ of mass loss at $100 \mathrm{~h})$, most of it during the first $6 \mathrm{~h}$ (54\% of mass loss). In FBS, Fg-3D degraded less (42\% of mass loss at $100 \mathrm{~h}$ ) but exhibited a similar degradation rate during the first $6 \mathrm{~h}$ ( $40 \%$ of mass loss) to the one observed in water. The cytotoxicity of Fg-3D was evaluated following the recommendations in the ISO10993-5 standard. It was estimated by quantifying the metabolic activity of MC3T3 (murine pre-osteoblasts) cells after $24 \mathrm{~h}$ in culture with scaffolds (direct contact) or with extracts of Fg-3D, and expressing the results as a percentage relative to tissue culture plastic control conditions. Higher concentrations of Fg-3D extracts (75\% and 100\%) seemed to cause stress to the cells, but the loss of metabolic activity was less than 30\% (Fig. 3D). Moreover, cells in direct contact with a scaffold or in media containing $25 \%$ or $50 \%$ extracts presented a small increase (up to $18 \%$ ) in their metabolic activity after $24 \mathrm{~h}$ of incubation.

\subsection{Fg-3D stimulated bone repair/regeneration}

The osteogenic potential of Fg-3D was tested in vivo using a critical bone defect model in the rat (Fig. 4A). The follow up, was performed 6 days and 8 weeks post-implantation. A favourable evolution of the repair process was observed in presence of Fg-3D 
A
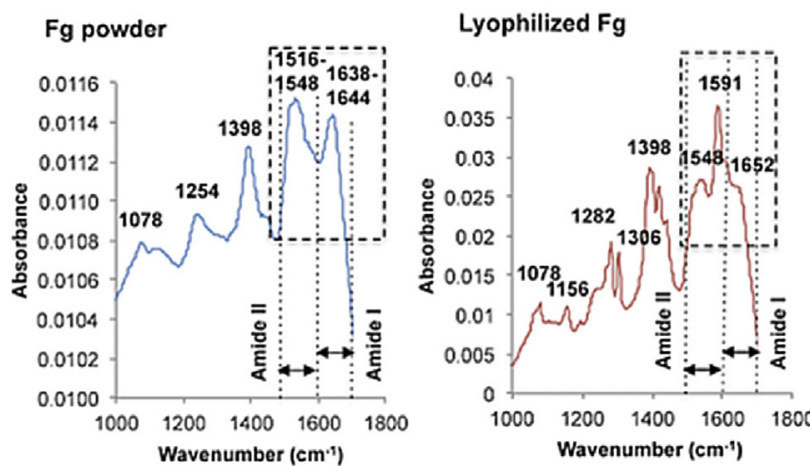

\section{Neutralized Fg (Fg-3D)}

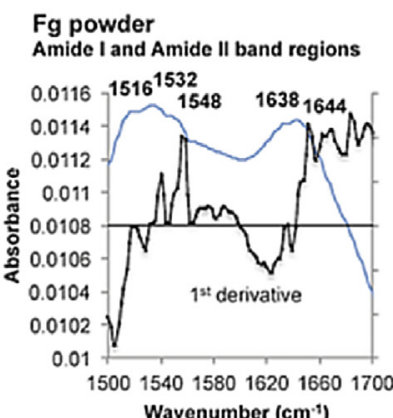

\section{Lyophilized Fg}

Amide I and Amide II band regions

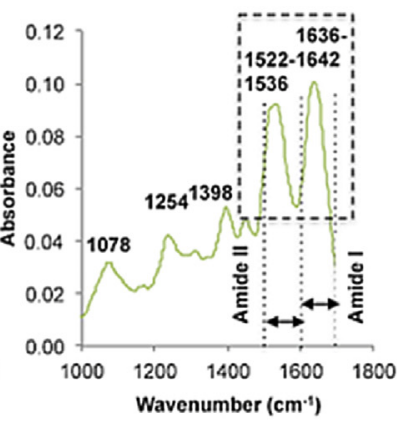

B

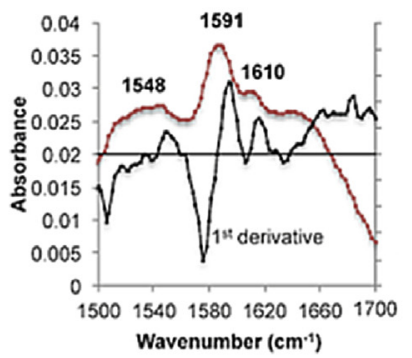

\section{Neutralized Fg (Fg-3D)}

Amide I and Amide II band regions

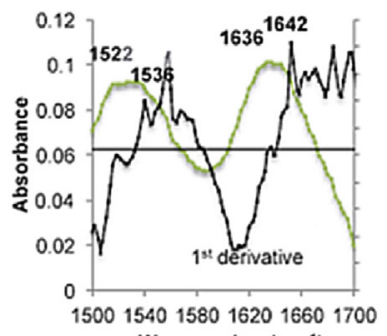

Wavenumber $\left(\mathbf{c m}^{-1}\right)$

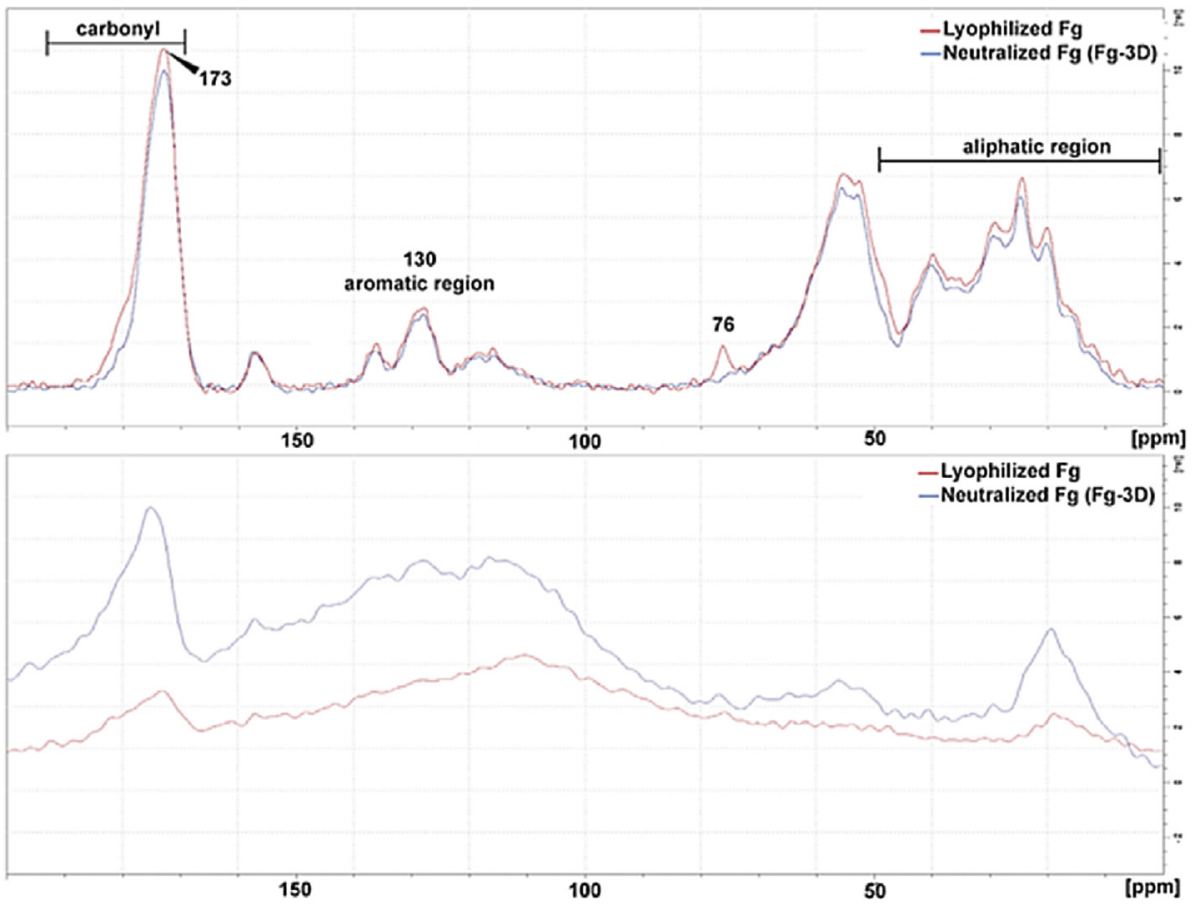

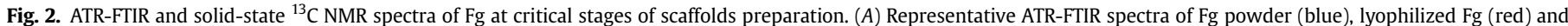

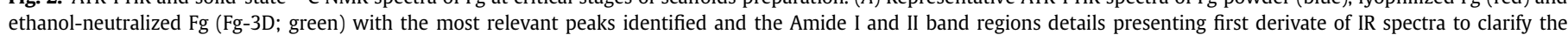

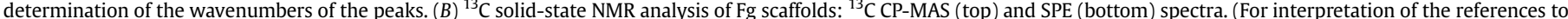
colour in this figure legend, the reader is referred to the web version of this article.)

(Fig. 4B). At 6 days post-injury Fg-3D led to an increased number of cells related with granulation tissue (GT) infiltration in the centre of the defect, while few cells and no granulation tissue were detected in the animals where no biomaterial was implanted (empty). The images reveal that acute immune response had already subsided, as PMN were hardly detected in either group. Furthermore, Fg-3D appear well-preserved and in intimate contact with surrounding bone, without visible fibrous capsule. After 8 weeks of implantation new bone tissue had formed, filling in the defects, and Fg-3D were no longer observable. Moreover, no chronic immune reaction was detectable. Residual granulation tissue was still identifiable in four out of five animals implanted with Fg-3D, particularly closer to the 
A

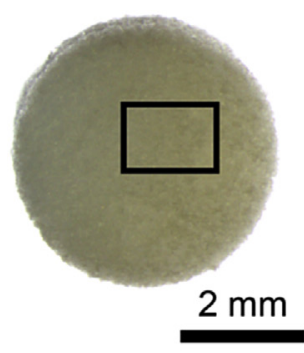

C

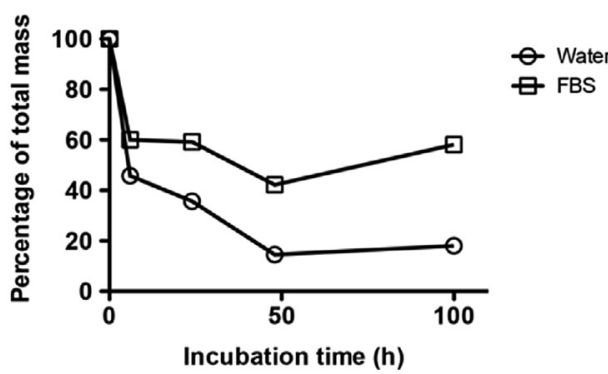

B

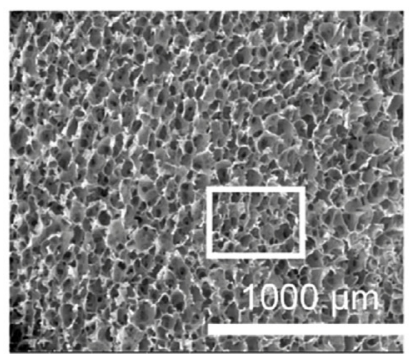

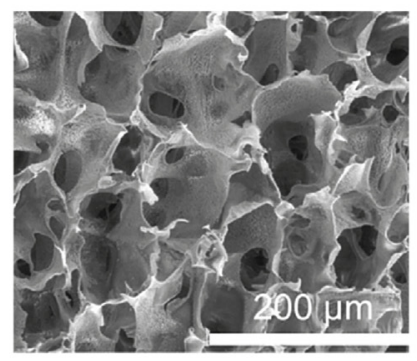

D

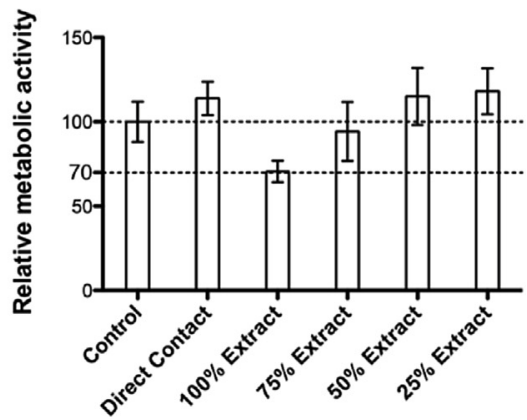

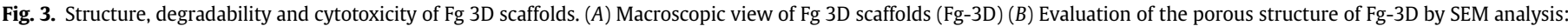

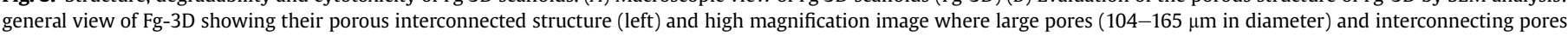

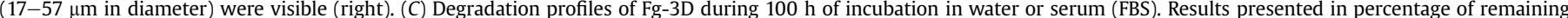

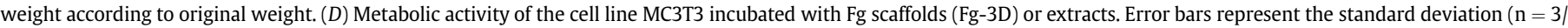
condition). Kruskal-Wallis test was used to compare the data.

surface of the defect, and surrounded by newly formed bone tissue and bone marrow. The newly formed bone was mostly woven bone, presenting a disorganized structure and enriched in collagen (blue stained fibres). Mature bone was also observed, with a distinctive trabecular organization, oriented along the lines of stress. The new trabecular bone formed in the defect region was functional, since bone mineralization regions, with ALP activity, and bone resorption pits with osteoclasts (TRAP positive cells; Fig. 4C) were observed, indicating that bone was going through remodelling. Bone remodelling is a dynamic process, requiring coupling between bone apposition and resorption processes, and Fg-3D seems to control the initial immune response to injury, while supporting bone repair/regeneration.

In order to further confirm the new bone formation observed by histological analysis, we performed micro-CT analysis. This corroborated the induction of new bone formation and additionally revealed periosteal repair in femurs implanted with $\mathrm{Fg}-3 \mathrm{D}$, at 8 weeks post-injury (Fig. 5A). In detail, the quantification of calcified tissue in the original defect region (dashed line) revealed that two out of three animals of the Fg group showed higher bone density and bone volume than animals with empty defects (Fig. 5B and C). Moreover, all injured animals showed higher trabecular bone separation $(\mathrm{Tb} \cdot \mathrm{Sp}$ ) and trabecular number $(\mathrm{Tb} \cdot \mathrm{N})$, when compared to the non-operated animal (Fig. 5D and E). Importantly, Fg-3Dtreated animals showed a tendency to present a higher trabecular bone thickness $(\mathrm{Tb} \cdot \mathrm{Th})$ compared to empty animals $(\mathrm{p}=0.1$, Fig. 5F), which is likely related to the bone remodelling that is still occurring 8 weeks post-injury. Together, histological analysis and micro-CT evaluation showed that Fg-3D supported bone repair with formation of new and thicker bone trabeculae, which contributed to the closure of the bone defects.

\subsection{Fg-3D modulates cytokine production}

In order to understand the mechanisms involved in stimulation of bone repair/regeneration induced by Fg-3D, the expression levels of inflammatory and pro-regenerative related genes at the bone defect site were evaluated 6 days after injury. Bone/implant cylinders were cut to include the bone defect with the implant and some of the surrounding tissue and then analysed for gene expression. Regarding inflammatory cytokines, a significant upregulation of both IL- 6 and IL- 8 ( $p<0.05$ ), but not of IL- $1 \beta$, was observed for both empty defects and Fg-3D, in comparison with non-operated animals (NO; Fig. 6A-C). Other cytokines that could be involved in regulation of an immune response, IL-2, IL-4, IL-10, TNF- $\alpha$ and IFN- $\gamma$, were not detected. Gene expression of growth factors involved in angiogenesis and bone remodelling was also analysed. Similar levels of osteocalcin (OC) were observed for all tested groups (Fig. 6D). A tendency for transforming growth factor beta 1 (TGF- $\beta 1$ ) up-regulation in operated animals was registered, though not statistically significant (Fig. 6E). On the other hand, VEGF was up-regulated in operated rats whose defect remained empty comparatively to NO animals ( $p<0.01$; Fig. $6 \mathrm{~F}$ ), but there were no statistically significant differences to the Fg-3D group. This difference in the extent of reactive angiogenesis, that is part of the response to injury, may be explained by the stronger inflammatory response in empty animals, that is dampened in Fg-3D implanted animals.

The systemic concentration of TNF- $\alpha$, IL- $1 \beta$, IL-17a, IL- 6 and TGF$\beta 1$ was evaluated in the plasma, since they are crucial mediators of immune responses and regenerative processes. No detectable levels of TNF- $\alpha$, IL-17a and IL-6 were found in plasma for any of the animals. Systemic levels of IL-1 $\beta$ (Fig. 6G) were significantly decreased for the Fg-3D group at 8 weeks post-implantation, when 
A
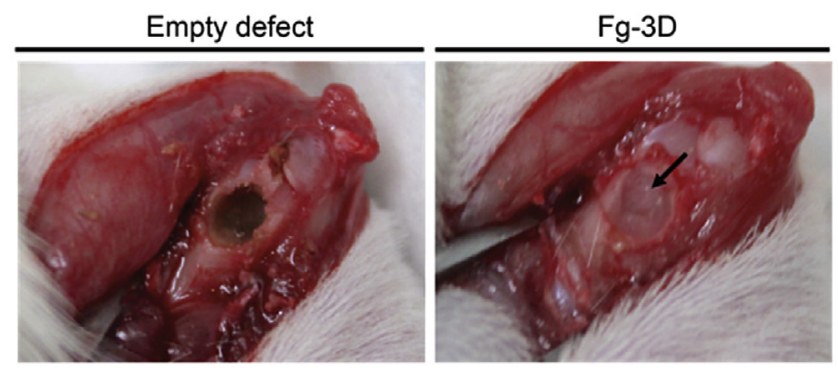

B
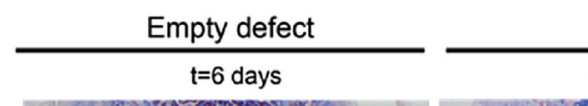

Fg-3D

$\mathrm{t}=6$ days
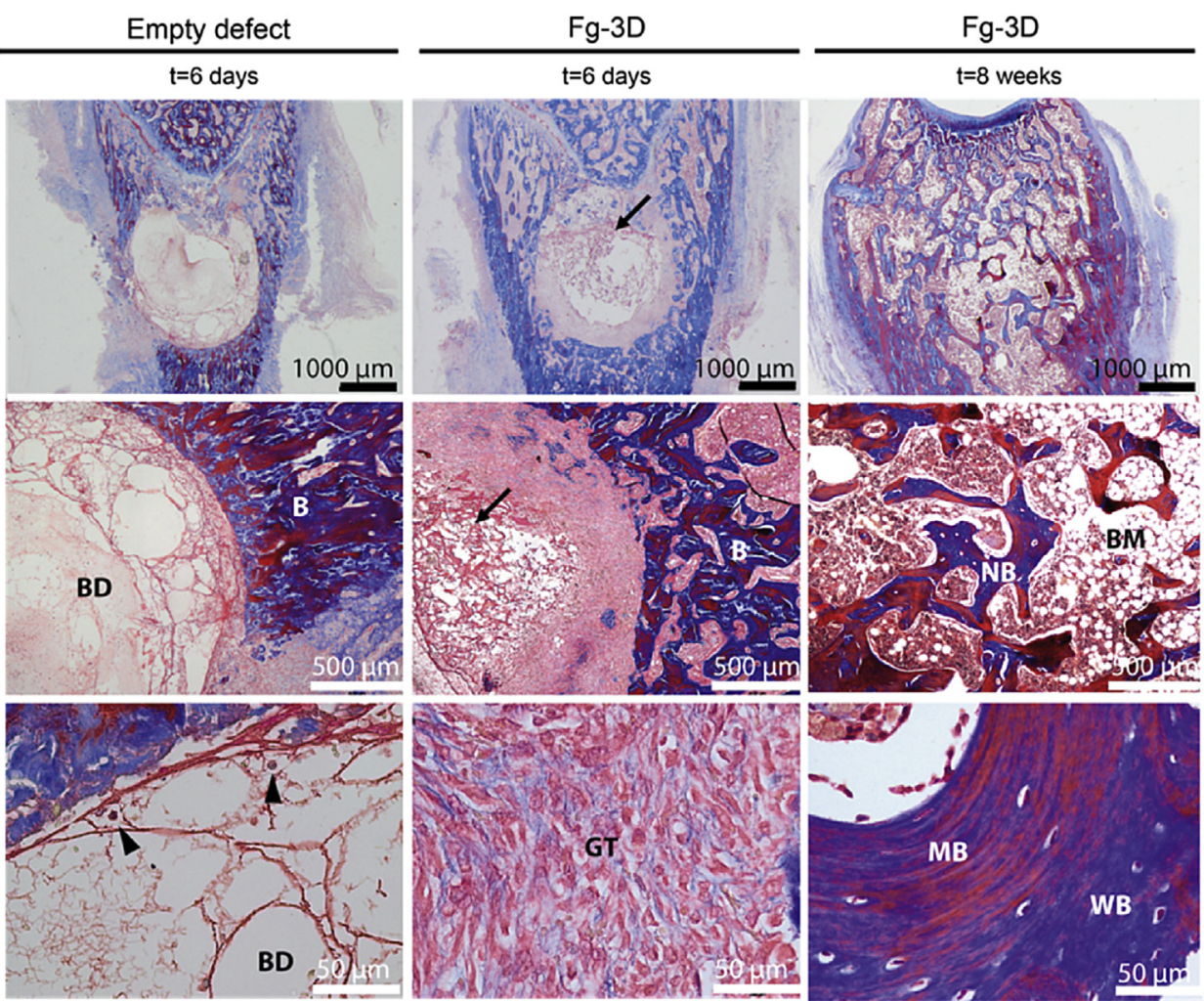

C
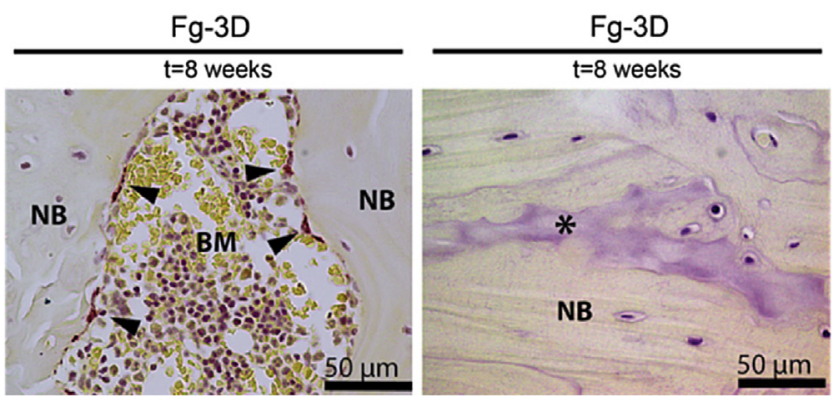

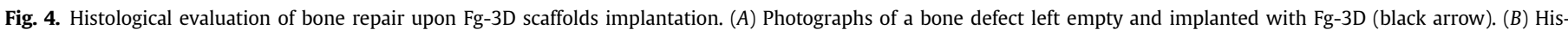

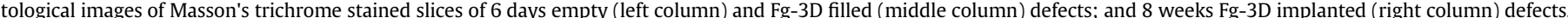

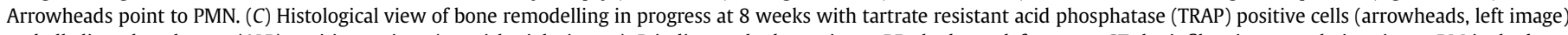

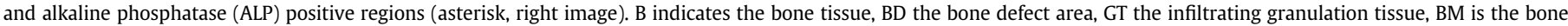
marrow, NB notes new bone, while WB corresponds to woven and MB to mature bone.

compared to Fg-3D at 6 days and with a strong tendency to be decreased, when compared to the Empty at 8 weeks $(p=0,0521)$ and the NO ( $p=0,0600)$ groups. Also, systemic levels of TGF- $\beta 1$ (Fig. $6 \mathrm{H}$ ) were significantly higher for empty-defect animals at 6 days post-injury and for Fg-3D animals at 8 weeks post- implantation, both when compared with NO animals. The timedependent modulation of TGF- $\beta 1$ production is likely involved in the wound healing processes, and its sustained increase up to 8 weeks in the animals implanted with Fg-3D may contribute to the regenerative response observed. 
A

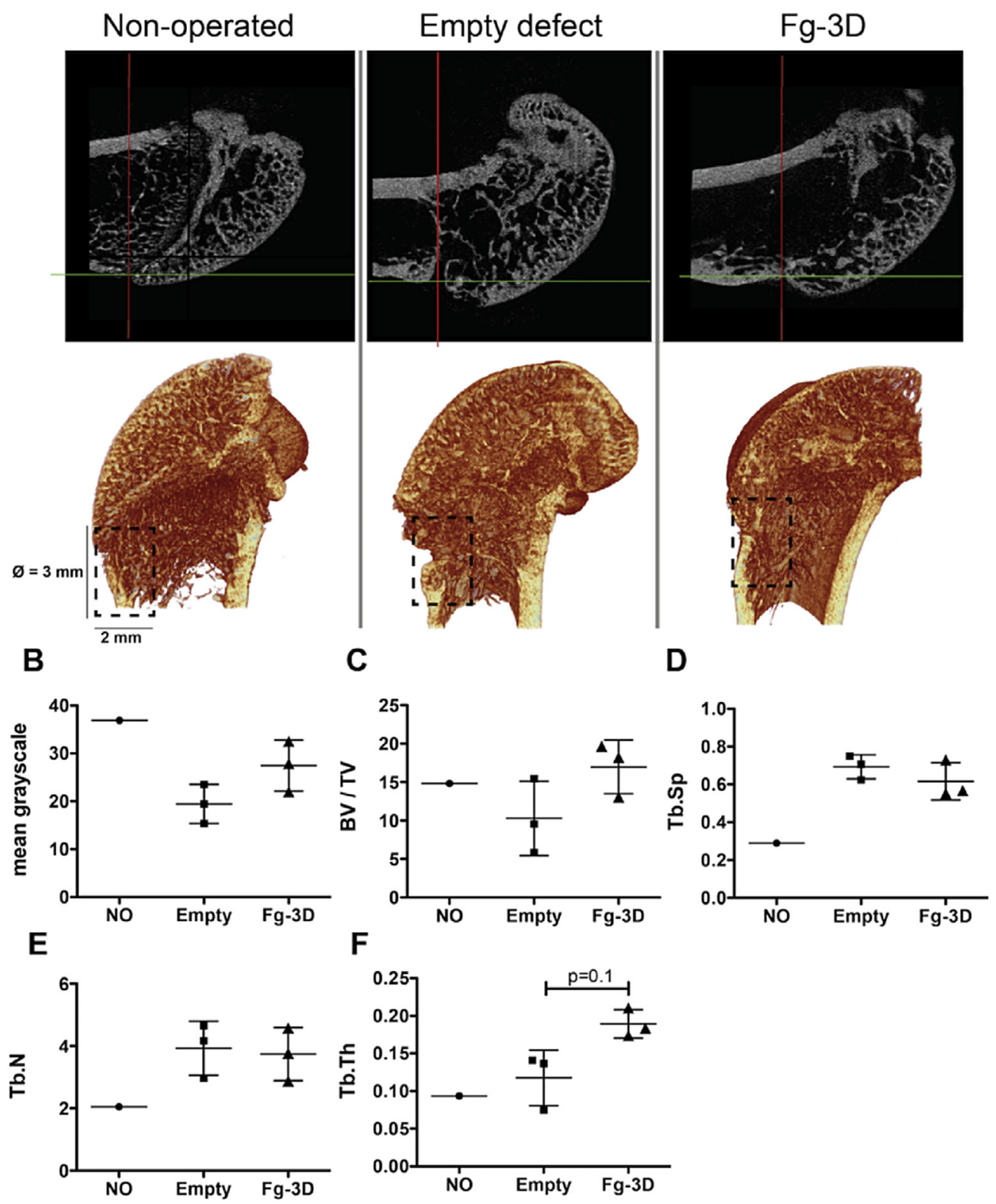

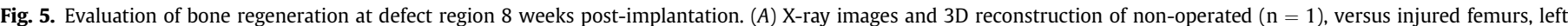

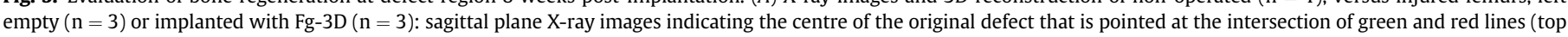

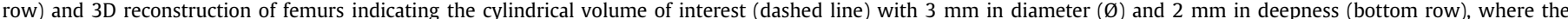

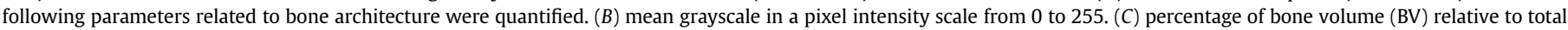

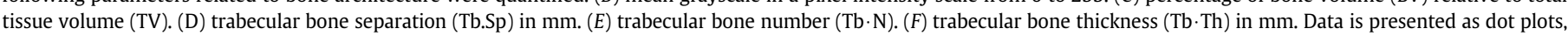

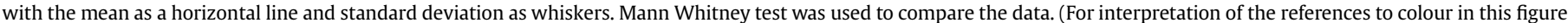
legend, the reader is referred to the web version of this article.)

\subsection{Implantation of Fg-3D leads to sustained alterations in systemic immune responses}

In order to evaluate the impact of Fg-3D on the systemic immune response, blood, spleen and draining lymph nodes were recovered to study the proportions of the different immune cell populations. Representative plots of the flow cytometry analysis illustrating the gates and surface markers used to evaluate the different immune populations are presented in supplementary data (Fig. S4).

The proportions of the different immune cell populations were analysed at 6 days post-implantation, in blood (BL), spleen (SP) and lymph nodes (LN) (Fig. 7). The response induced by the bone injury itself (empty group), when compared with NO animals was mild, and by comparison, the Fg-3D implanted group showed some significant differences to $\mathrm{NO}$ and in some cases also to empty animals. In BL and SP, empty and Fg-3D groups followed the same tendency for the most abundant subsets, increased T cells and decreased $B$ cells (Fig. 7A). While in BL the reduction was also significant for NK, NKT and myeloid cells, particularly for Fg-3D implanted animals, in SP these populations did not show significant differences (Fig. 7A and B). On the other hand, in draining $\mathrm{LN}$ the response of empty and Fg-3D groups was in opposite directions, at least for the most abundant T and B cell populations. Empty defects led to increased B 
A

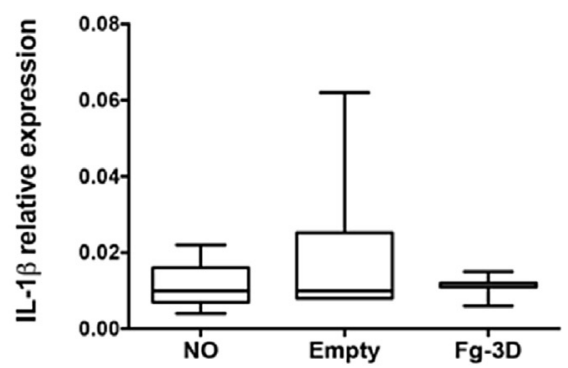

D

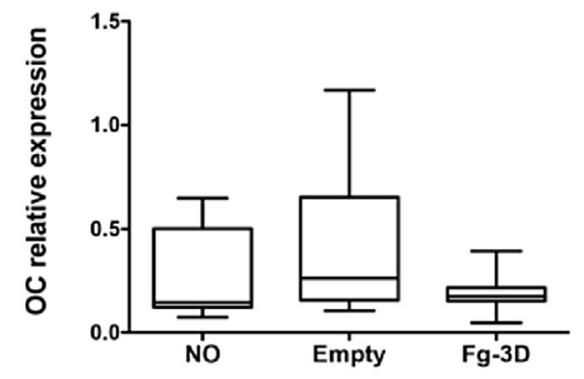

G

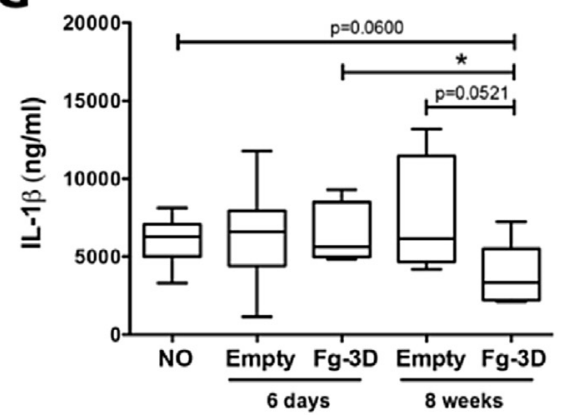

B

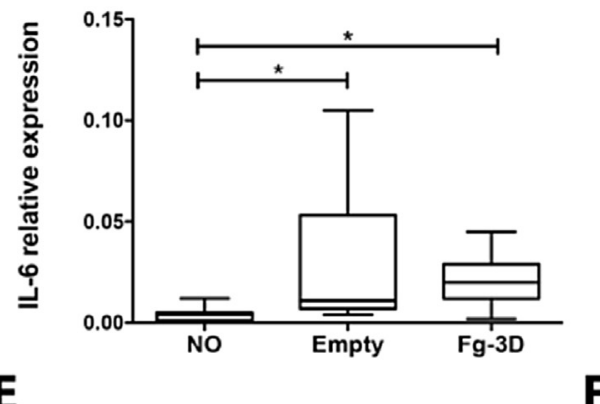

E

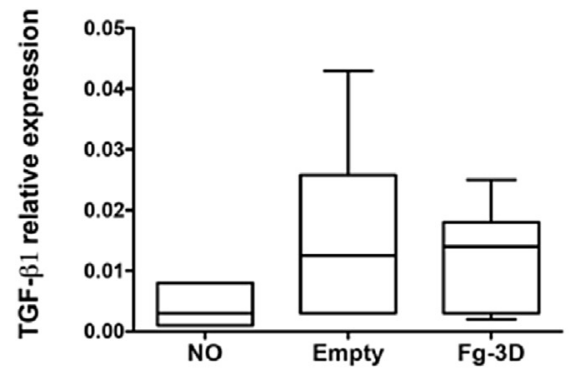

H

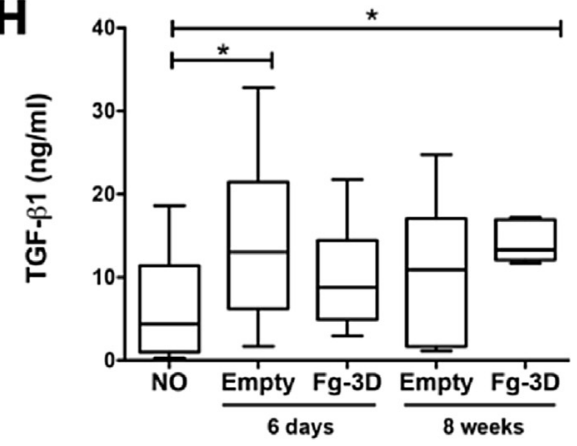

C

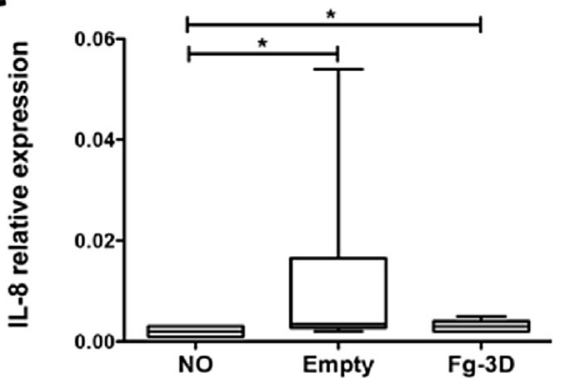

$F$

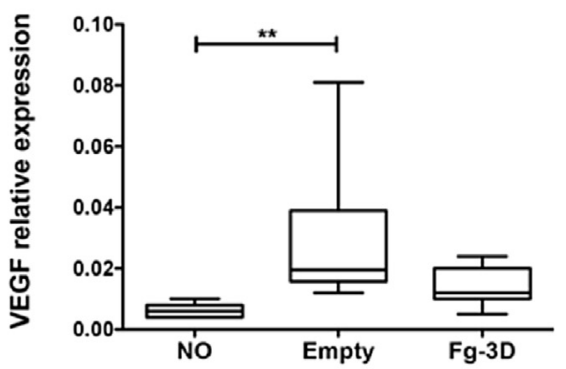

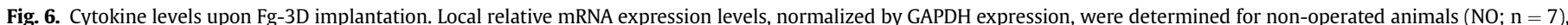

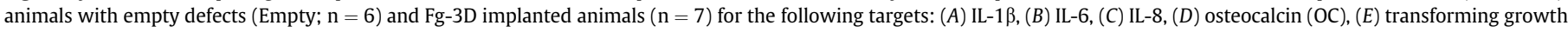

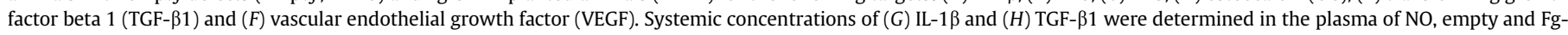

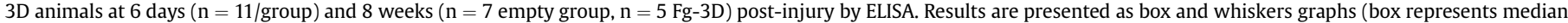
and quartiles while whiskers represent min to maximum values); ${ }^{*} \mathrm{p}<0.05$ and ${ }^{* *} \mathrm{p}<0.01$. Mann Whitney test was used to compare the data.

cells and decreased $\mathrm{T}$ cells, while the Fg-3D implanted group remained closer to NO and significantly different from empty in the $\mathrm{B}$ cells. Additionally, the percentage of $\mathrm{T}$ cells with downregulated $\mathrm{TCR}\left(\mathrm{TCR}^{\mathrm{dim}}\right)$, which can be correlated with $\mathrm{T}$ cell activation, was lower in the SP of animals with Fg-3D, when compared with NO animals. The proportions of $\mathrm{CD} 4^{+} \mathrm{T}$ cells and $\mathrm{CD} 8^{+} \mathrm{T}$ cells were similar between different groups in BL, LN and SP.

We then examined the cells expressing Mac-1 (CD11b/c $\mathrm{c}^{+}$/ $\mathrm{CD}_{18}^{+}$), the receptor for Fg [12,32], and found that Mac-1 expression was significantly decreased in the BL, LN and SP of animals implanted with Fg-3D, in comparison with animals with an empty defect (Fig. 7C). CD4 and CD8 co-receptors are reported to enhance FcR responses in myeloid cells [33], so we analysed if myeloid cell decrease preferentially occurred within CD4 or CD8 positive populations. The results obtained indicate that implantation of Fg-3D led to a reduction in the percentages of $\mathrm{CD}^{+}$cells amongst $\mathrm{CD} 11 \mathrm{~b} / \mathrm{c}^{+}$cells in all assessed tissues from animals with Fg-3D when compared with animals with empty defect (Fig. 7B). A significant decrease of the percentage of $\mathrm{CD}^{+}$cells, within the $\mathrm{CD} 11 \mathrm{~b} /$ $\mathrm{C}^{+}$population, in animals of the Fg-group, was also found, but only in SP. Furthermore, the percentage of positive cells for MHC class II (MHC-II), a molecule expressed mainly on the surface of antigen presenting cells, was also analysed (Fig. 7C). Fg-implanted animals presented lower percentages of $\mathrm{MHC}-\mathrm{II}^{+} \mathrm{CD} 11 \mathrm{~b} / \mathrm{c}^{+}$cells, in BL, LN and SP in comparison with NO group. In addition, the percentage of MHC-II ${ }^{+}$cells within $\mathrm{CD} 11 \mathrm{~b} / \mathrm{c}^{+}$cells showed also a tendency to decrease in empty and Fg-3D groups when compared to NO animals, but differences were only statistically significant in the BL, when comparing Fg-3D with NO groups. Overall, these results clearly show that implantation of Fg-3D impacts the host response at systemic level, involving different immune cell populations and their activation status.

The systemic immune cell populations were also analysed at 8 weeks post-implantation, by looking at the percentages of B cells, T cells and myeloid cells (Fig. 8). These cell populations had been found to be altered in the BL and $\mathrm{LN}$ in response to Fg-modified implants in this late time point [7]. In this study it was interesting to observe that the decreased frequencies of $\mathrm{B}$ cells and myeloid cells in the BL at 6 days were still observed 8 weeks after injury in the Fg-3D group. In the LN of animals with Fg-3D, the percentage of B cells was still decreased 8 weeks post-injury, while the percentage of T cells is increased $(79.28 \%$ in NO vs. $85.50 \%$ in $\mathrm{Fg}$ 3D). In parallel to the ongoing process of bone repair observed at 8 weeks in the Fg-3D group, the changes induced by Fg-3D in 
A
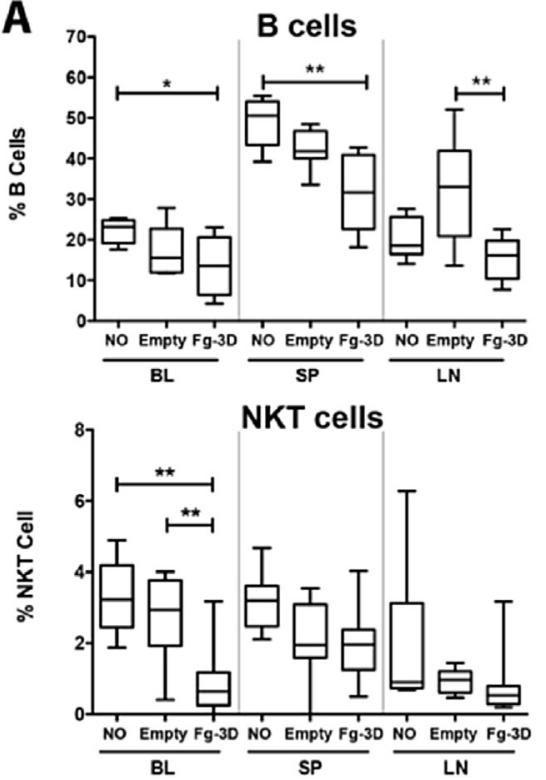

B
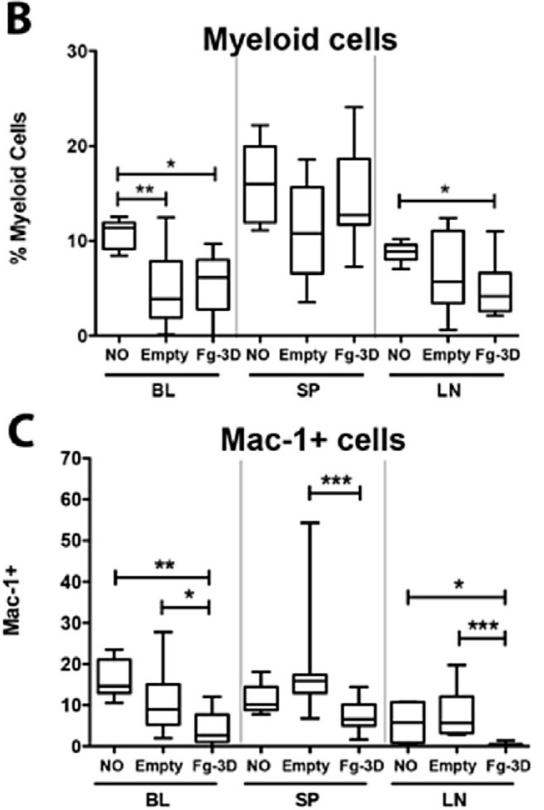
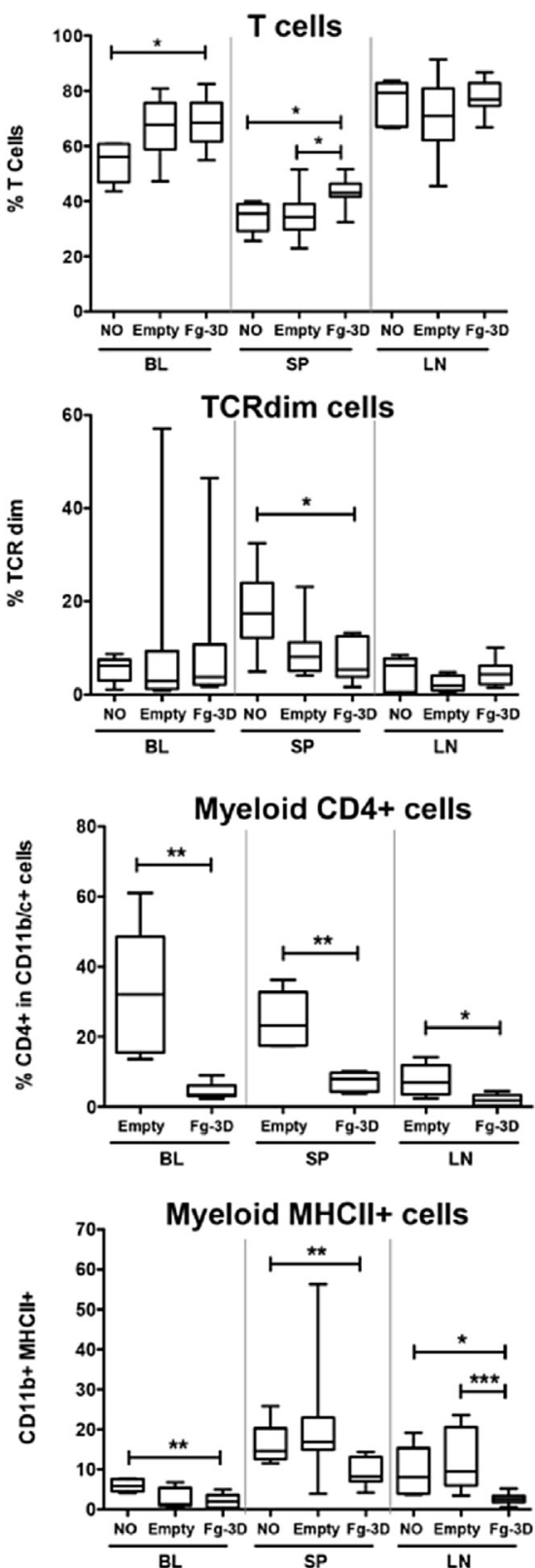

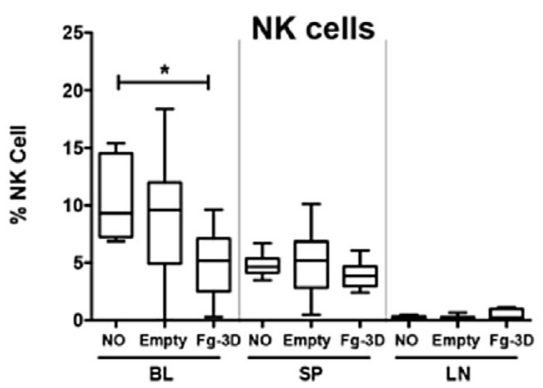

CD4 and CD8 T cells
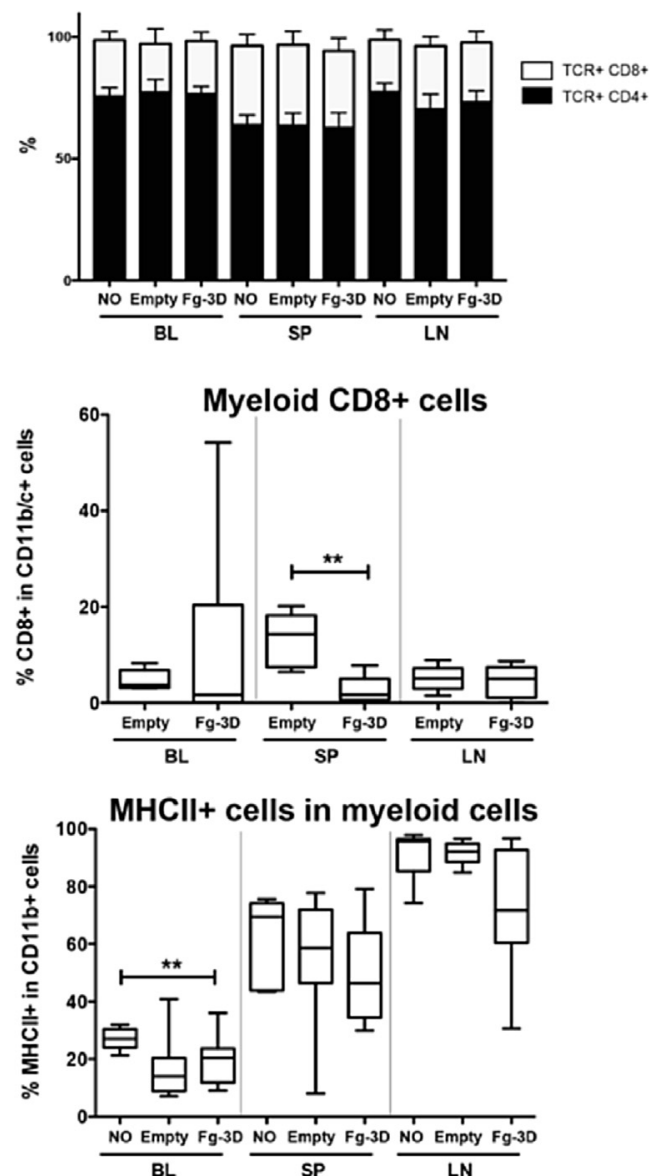

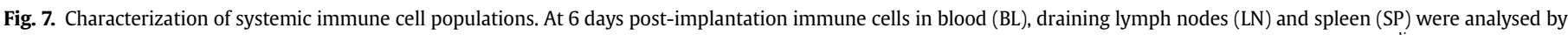

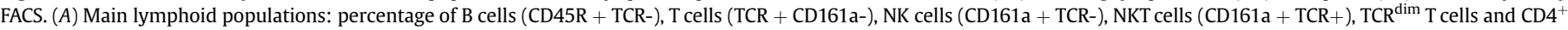

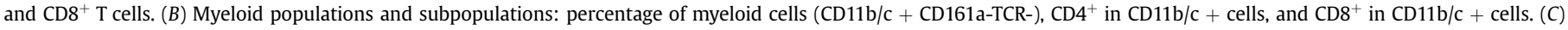

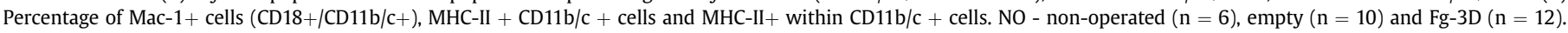

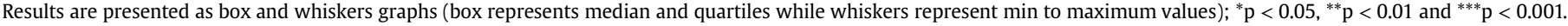
Kruskal-Wallis test (or ANOVA when data distributions were normal) were used to analyse the data.

immune cells populations in BL and LN are still detectable, suggesting a relation between the two biological events.

\section{Discussion}

In this study, we have found that scaffolds made of fibrinogen (Fg-3D) promote bone repair and impact the inflammatory and immune responses both at local and systemic levels. We have observed a pro-regenerative local environment, with a resolving inflammatory response and granulation tissue formation at 6 days after implantation of Fg-3D. This translated to extensive bone repair at 8 weeks post injury. Importantly, bone tissue healing observed in the presence of Fg-3D was correlated with significant changes in the systemic immune cell balance. We believe that this is a crucial aspect of the response to biomaterials, that has been generally overlooked in other studies.

To the best of our knowledge, the current study is the first one describing the preparation of pure Fg scaffolds by freeze-drying, without using exogenous enzymes. Here, we present a biomimetic approach where Fg lyophilized scaffolds are neutralized using ethanol in order to reduce their solubility, easing their manipulation and implantation. Neutralization using ethanol resembles the application of methanol in the development of 3D matrices of fibroin [34]. Previously, other groups [18,19,35,36] have 
A

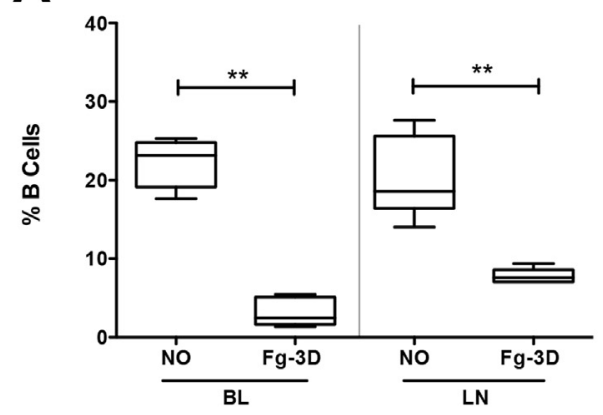

B

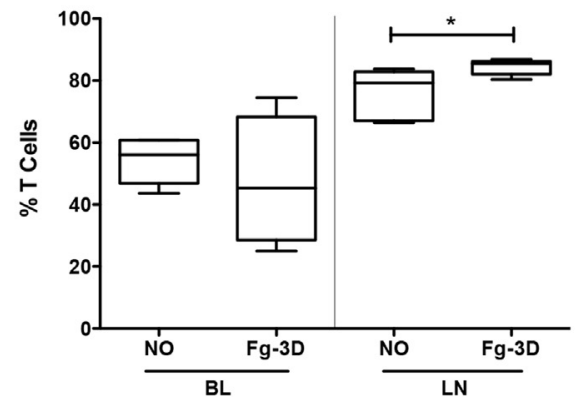

C

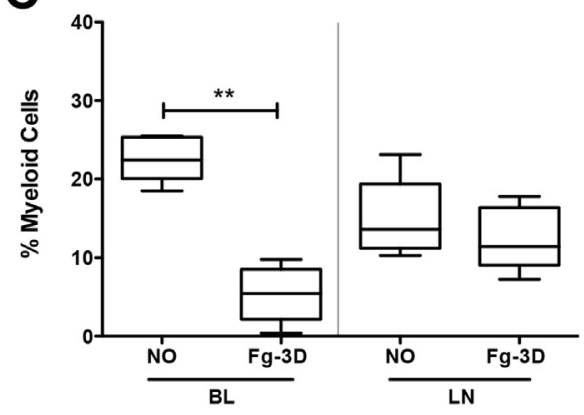

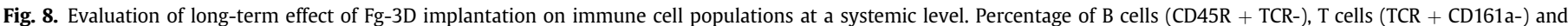

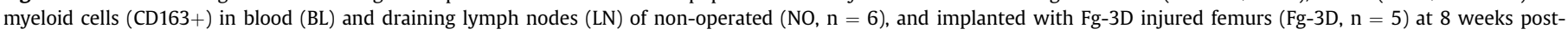

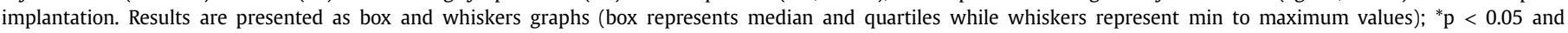
${ }^{* *} \mathrm{p}<0.01$. Mann Whitney test was used to compare the data.

prepared solutions of $\mathrm{Fg}$ and exogenous thrombin, leading to polymerization into fibrin networks, carried out outside the animal. Ethanol precipitated porous Fg scaffolds, further crosslinked with genipin have also been produced by microsphere templating, and compared to thrombin polymerized ones [37]. However, the authors proceeded to more extensive in vitro and in vivo characterization only with the thrombin polymerized materials [38].

Our rationale for not using thrombin was to develop a new, simpler and cheaper biomaterial, without the problems associated with the use of exogenous thrombin. As reviewed by Lew WK et al., thrombin delivery may elicit adverse immune reactions and the coinjection of thrombin increases the risk of thrombosis [39]. However, as thrombin is present at injury settings, we investigated if it could further stabilize Fg-3D structure. FTIR analysis of Fg-3D performed before and after incubation with thrombin, revealed similar spectral profiles (Fig. S5), indicating that added thrombin does not lead to significant changes in the molecular conformation of Fg. Although we cannot completely rule out that host endogenous thrombin can contribute to further stabilize the Fg-3D structure, we believe that any contribution of endogenous thrombin would be advantageous for the biomaterial and its integration with the surrounding tissue.

The spectrum obtained here for Fg powder was in agreement with previous studies [30]. The findings obtained for lyophilized Fg scaffolds are in line with the reversible changes in secondary structure of proteins induced by lyophilization, namely increasing $\beta$-sheet content and decreasing $\alpha$-helix content, previously reported by others [40]. Upon neutralization, Fg-3D presented an IR spectrum similar to Fg powder but the detailed Amide I and Amide II band structure of neutralized Fg scaffolds suggested a slight increase of $\beta$-sheet content, consistent with the transition from $\alpha$ helix to $\beta$-sheet described for fibrin formation [31]. In fact, similar peaks, albeit less intense, were observed when our Fg solution was polymerized using thrombin (Fig. S5).

On the other hand, the reduction observed in the intensity peak in carboxylate side chains in Fg-3D may explain their lower solubility in comparison to the lyophilized Fg scaffolds or Fg powder. Fg carboxyl groups participate in fibrin formation (polymerization pocket "a" is located at carboxyl region), and may affect cell adhesion (cellular integrins interacts with carboxyl-terminal RGD) [41,42]. Moreover, NMR spectroscopy revealed that the peak at $76 \mathrm{ppm}$ in the CP-MAS spectrum is no longer visible after Fg scaffolds neutralization. This peak at $76 \mathrm{ppm}$ in the CP-MAS spectrum may arise from the small amounts of carbohydrate moieties that bind to $\mathrm{Fg}$, that is, $\mathrm{N}$-acetylglucosamine, mannose, galactose, $\mathrm{N}$ acetylneuraminic acid. The fact that this peak is no longer visible after neutralization suggests that the sugars moieties in neutralized Fg scaffolds become significantly more mobile, while the rigid glycoprotein domains become more organized or crystalline. Notably, no significant conformational changes are observed in the rigid protein environment, since the conformation-dependent carbonyl region in the CP-MAS spectra remains unchanged (peak at $173 \mathrm{ppm}$ with shoulders at 175, 177 and $180 \mathrm{ppm}$ ), probably due to the large bandwidth noted.

Fg-3D scaffolds presented an interconnected porous network, similar to the one obtained for chitosan scaffolds produced using similar methodology [7]. The macro pores observed in Fg scaffolds likely support cell migration, bone ingrowth and capillaries formation while micro pores favour a suitable hypoxic microenvironment for the cartilage formation that occurs during osteogenesis, as described for other biomaterials [43]. The in vitro degradation of Fg-3D mostly occurred during the first $6 \mathrm{~h}$ and was faster in water than in presence of FBS. This behaviour was most likely due to a protective role of calcium ions and residual thrombin present in FBS towards the Fg-3D [44]. The results obtained when culturing pre-osteoblastic cells with $\mathrm{Fg}$-3D extracts indicate that the material was not cytotoxic, according to the ISO10993-5 standard.

When Fg-3D scaffolds were implanted in a femoral bone defect, the histological evaluation performed 6 days post-injury revealed that the scaffold structure was still present. It is possible that a fraction of the fibrinogen in Fg-3D could be polymerized by the host thrombin present at defect region. However, any potential polymerization was not extensive, as the porous scaffold structure is still similar to non-implanted materials (Fig. 3B and Fig. S1), and different from the endogenously formed fibrin mesh identified in the empty defects. Moreover, the histological findings support that Fg-3D eased cell migration and induced granulation tissue infiltration, correlating with a decrease in the size of the defect area. Importantly, in the context of bone healing, granulation tissue replaces hematoma during the early stage of bone repair $[45,46]$. Previous reports showed that Fg cell-binding domains can promote migration [11] and proliferation [47] of human fibroblasts, a key cell population involved in granulation tissue formation and wound healing [48].

Eight weeks upon implantation, newly formed bone was detected, presenting bone marrow cavity-like morphology. In some animals residual highly vascularized soft tissue could still be observed in the centre of the defect, which may be related with the fact that bone repair occurs from the periphery to the central region of the defect [49]. No trace of the Fg-3D was observed 8 weeks postimplantation, suggesting scaffold biodegradation by fibrinolysis 
without impairing tissue regeneration. When compared to our previous results, using chitosan-based materials modified or not by Fg adsorption, in the same animal model and at the same time postimplantation [7], the outcome here reveals a much more advanced stage of bone formation and repair, with complete degradation of Fg-3D material and its replacement with new bone, in the vast majority of the defect area.

Bone repair was further characterized by micro-CT, revealing that animals implanted with Fg-3D were at an early stage of bone healing, having formed compact bone tissue in the defect region. This compact bone is expected to be gradually remodelled to trabecular bone. Mature bone is structurally more porous and presents lower percentages of calcified tissue, as observed in the micro-CT of the non-operated animal, whose bone parameters were in agreement with the literature [50,51]. Importantly, Fg-3D implanted, but not empty defect, animals presented periosteal repair, which is reported to have a positive effect on biomechanics and bone healing, as it constitutes an important reservoir of bone cell precursors [52,53]. The bone repair process described here is in line with what has been found in vivo after implanting fibrin glue combined with cells or calcium phosphate particles in a critical rabbit calvarial bone defect model [35,54]. Conversely, a previous study in the mouse calvarial defect reported that fibrin porous scaffolds, produced by sphere templating and thrombin polymerization, only promoted new bone formation when modified to incorporate calcium phosphate [38]. Interestingly, although their evaluation was at 45 days post-implantation, by that point the fibrin material was already undetectable at implant site. In the current study Fg-3D scaffolds were implanted alone, relying on the host cells to promote self-regeneration of bone tissue.

The local gene expression results indicate a mild inflammatory response in empty animals that is not augmented when Fg-3D are present. Our findings on the local immune response indicate that the bone injury seems to be the driving force underlying the increase of IL-8, IL- 6 and IL-1 $\beta$. Cytokines such as IL- 4 and IL-10, which have anti-inflammatory roles were not detected 6 days post-injury at the mRNA level. This is in line with a previous report on bone injury in a sheep model, where the highest mRNA IL-10 levels were found $24 \mathrm{~h}$ post-osteotomy followed by decreasing levels of this cytokine until the end of the experiment $(60 \mathrm{~h})$ [6]. The slight increase of IL-8 levels locally detected may be related to the chemoattraction of PMN, which were histologically identified. A significant increase of IL-6 mRNA levels was observed in the bone defect of both operated groups, while plasma IL-6 levels were bellow detection in all groups (data not shown). IL-6 is a pleiotropic cytokine and its role in bone healing, namely in the early stage, is believed to be related with angiogenesis and osteoclastogenesis, whose malfunction delays bone maturation [55]. Interestingly, augmented levels of local and systemic IL- 6 and IL- 8 concentrations have been found in patients with bone trauma [56]. Other proinflammatory cytokines such as IL-17a, associated with graft rejection and autoimmunity, or TNF- $\alpha$, highly related with exacerbated inflammation and infection, were not detected in the plasma of these animals (data not shown). Of note, the presence of Fg-3D significantly homogenized the host response, dampening the immune reaction. This can be confirmed by a lower coefficient of variation of the Fg-3D implanted group, for the majority of the different molecules evaluated by gene expression analysis, FACS and ELISA (Supplementary Table 2).

Although at 6 days no significant differences were observed in local IL-1 $\beta$ mRNA levels or systemic protein levels, a significant reduction of IL-1 $\beta$ in plasma was found at 8 weeks postimplantation for Fg-3D group. These findings are in line with the literature as the first peak of IL- $1 \beta$, induced by the initial immune response, is expected to occur $24 \mathrm{~h}$ after the injury and a second peak 3 weeks later [57]. At later stage, IL-1 $\beta$ is reported to be mainly produced by osteoblasts during bone remodelling [57]. In this sense, the lower concentration of IL-1 $\beta$ in the plasma of the animals implanted with Fg-3D should be likely related to the stage of bone repair observed at 8 weeks post-implantation.

TGF- $\beta 1$ has been reported as an instrumental player in a balanced bone remodelling [58]. The results obtained showed a tendency for TGF- $\beta 1$ increase at early time-points locally at mRNA level, and systemically at the protein level. Interestingly, its protein levels in plasma remained high for Fg-3D implanted animals at 8 weeks post-implantation, when compared with $\mathrm{NO}$ animals. This is in line with our previous results showing an increase in plasma levels of TGF- $\beta 1$ at 8 weeks post-implantation, when bone regeneration was promoted using Fg-modified chitosan implants [7]. Additionally, TGF- $\beta 1$ is considered an immunoregulatory factor due to its effects on immune cell populations. Regulatory $\mathrm{T}$ cells produce TGF- $\beta 1$ and IL-10 to inhibit other T cell populations [59], and TGF- $\beta 1$ signaling in T cell affects bone metabolism [60]. The function of B cells may also be modulated by TGF- $\beta 1$ [61]. Moreover, TGF- $\beta 1$ induces and regulates the recruitment of myeloid cells, namely monocytes $[62,63]$, and is produced by the pro-healing M2 macrophages.

Angiogenesis is expected to occur during bone repair involving the angiogenic factor VEGF, whose production is reported to be stimulated in presence of Fg [14]. The mRNA levels of VEGF were significantly higher in the empty group than in NO animals, while Fg-3D animals showed intermediate expression levels. The peak of local up-regulation of VEGF expression has been seen to occur between 24 and $36 \mathrm{~h}$ after bone defect surgery followed by a decrease [6], and high VEGF production may be linked to inflammation.

Overall, the data obtained suggests that the bone defect induced a mild inflammatory response, which was not potentiated by Fg-3D implantation. The short-term evaluation at 6 days post-injury is a snapshot that allows evaluating the transition from acute inflammation to chronic inflammation. Thus, it cannot be excluded that some early biological events might have been missed, namely infiltration of neutrophils, $\mathrm{T}$ cells and $\mathrm{B}$ cells and occurrence of a peak in the local levels of cytokines (e.g. IL-1 $\beta$ and TNF- $\alpha$ ) $[5,6,64]$.

How key immune cell populations present in blood (BL), spleen (SP) and draining lymph nodes (LN) react to the critical bone injury and to the implantation of Fg-3D was of paramount importance to understand the host response to Fg-3D. In our previous work Fgadsorbed chitosan scaffolds prepared by freeze-drying were evaluated using the same animal model. Fg-adsorbed scaffolds led to a different systemic response with heighten percentage of B cells and myeloid cells (defined as $\mathrm{CD}_{163^{+}}$cells) with a decrease in the percentage of T cells in the draining LN [7] at 8 weeks. Interestingly, here the systemic immune response in Fg-3D implanted animals showed a decrease in the percentage of myeloid cells, B cells, NK and NKT cells and higher T cell proportional representation, may be related to bone tissue response to injury. The increased percentages of circulating and SP T cells in Fg-3D group and the concomitant decrease in the proportion of B cells in BL, LN and SP could be part of the new equilibrium within lymphoid populations to support bone debris scavenging, needed in these initial stages of bone repair. Previous reports have noted a local increase in T cells starting $24 \mathrm{~h}$ after fracture which is maintained until 21 days, as part of dynamics of immune cell infiltration in to the lesion site as elegantly described by [5]. Scaglione et al. reported an increase in circulating lymphocytes and platelets 4 days after subcutaneous biomaterial implantation, while circulating monocytes decrease [65]. In agreement with these findings we also observed an increase in T cells and decrease in myeloid cells 6 days after implantation. Other studies showed that augmented $\mathrm{CD}^{+} \mathrm{T}$ cells correlated with 
a poorer bone healing, which can be reverted upon depletion of $\mathrm{CD}^{+} \mathrm{T}$ cells $[66,67]$. Importantly, we did not find significant differences in $\mathrm{CD}^{+} \mathrm{T}$ cells, being the $\mathrm{CD} 4^{+} \mathrm{T}$ cells the predominant subset identified as expected. Moreover, Elisseeff's group recently proposed a pro-regenerative biomaterial through the modulation of the adaptive immune response. In this study, hypertrophic draining lymph nodes, accompanied by IL-4 expression, were observed in the animals with functional muscle tissue restore. Additionally, $\mathrm{CD} 4^{+} \mathrm{Th} 2 \mathrm{~T}$ cells were identified as the main subset involved in this systemic response while B cells and $\mathrm{CD}^{+} \mathrm{T}$ cells were suggested to be potentially involved [68].

In terms of immune cell activation markers, a decrease of $\mathrm{TCR}^{\mathrm{dim}}$ $\mathrm{T}$ cells with an increased proportion of splenic $\mathrm{T}$ cells of animals with Fg-3D may be correlated with reduced activation of T cells in this secondary lymphoid organ. This change in splenic T cell population was accompanied by a decrease in the proportion of CD45R expressing B cells, which could also be related with the loss of CD45R expression during differentiation to plasma cells, in response to the human $\mathrm{Fg}$, upon a T-cell dependent immune response, as previously described in mice [69]. As we are implanting human Fg in rat we cannot exclude the possibility of an immune response from the rat against the human protein, especially when considering that the homology percentages between human and rat fibrinogen varies from $52 \%$ to $66 \%$ [70]. However, the perfect integration of Fg-3D scaffolds in bone, the reduced immune cell infiltration at 6 days, and the absence of fibrous capsule at 8 weeks, all argue against a strong immune response in this sense. The decreased percentage of MHC-II ${ }^{+}$cells within the CD11b/ $\mathrm{c}^{+}$ population may reflect reduced levels of expression, which by becoming lower than the detectable minimum appear as negative. An increase of the percentage of $\mathrm{CD}^{+}, \mathrm{CD} 161^{+}$and $\mathrm{MHC}-\mathrm{II}^{+}$cells was observed in other studies, namely in graft rejection $[71,72]$. Therefore, the systemic decrease of the percentage of blood cells expressing MHC-II and CD11b/c in animals with Fg-3D scaffold might be related with a good integration of the implant in the bone.

Together, our findings support the pro-regenerative potential of Fg-3D and the systemic impact of injury and biomaterials implantation. Upon Fg-3D implantation, bone defect closure was faster and with periosteal repair, and promoted a more controlled biological response in comparison to the empty group. In future, new studies are required to acquire a comprehensive understanding how Fg-3D support bone healing and impact the immune system. This study is the first identifying the key immune cell populations and mediators, calling for further studies on the mechanisms and the role of these cell populations on establishing the proregenerative microenvironment.

\section{Conclusions}

The results discussed above show that Fg-3D scaffolds provided a temporary support and promoted a pro-regenerative microenvironment, which led to periosteal bone repair after 8 weeks of implantation. The significant changes observed draw attention to the systemic nature of response to injury and the potential for immunomodulation upon biomaterial implantation. The current study constitutes a basis for the development of Fg-based biomaterials, exploring $\mathrm{Fg}$ immunomodulatory properties for regenerative medicine.

\section{Acknowledgements}

This work was financed by the project (NORTE-01-0145-FEDER000012), supported by Norte Portugal Regional Operational Programme (NORTE 2020), under the PORTUGAL 2020 Partnership Agreement, through the European Regional Development Fund
(ERDF). AS, DV, MIO, CC were supported by PhD and Post-Doc fellowships SFRH/BD/85968/2012, SFRH/BD/87516/2012, SFRH/BPD/ $37090 / 2007$, SFRH/BDP/87071/2012, respectively. The NMR work was developed within the scope of the project CICECO-Aveiro Institute of Materials, POCI-01-0145-FEDER-007679 (FCT Ref. UID/ CTM/50011/2013), financed by national funds through the FCT/MEC and when appropriate co-financed by FEDER under the PT2020 Partnership Agreement. AMG also thanks Portuguese National Nuclear Magnetic Resonance Network, supported with FCT funds. The authors thank Griffons, S.A. for supplying thrombin.

\section{Appendix A. Supplementary data}

Supplementary data related to this article can be found at http:// dx.doi.org/10.1016/j.biomaterials.2016.10.004.

\section{Author contributions}

The research project was performed at i3S/INEB in the University of Porto. DMV, IOP, ARA, CRA and CCR carried out the preparation and in vitro characterization of fibrinogen scaffolds. The animal experiments, samples collection and data analysis were performed by DMV, RMG, CRA, MIO, NN, AMS, ACR and SGS. This work was done in collaboration with the Research Centre for Experimental Orthopaedics (Heidelberg University Hospital), where DMV, RMG, ES, KLK and WR performed gene expression and micro-CT analysis. AMG from CICECO (University of Aveiro) collaborated in this study by performing NMR analysis. DMV, SGS, RMG, CRA, ML, WR and MAB conceived the study, designed and coordinated the experiments and performed data analysis. These authors also drafted the manuscript and all authors contributed to and approved the final version of the manuscript.

\section{Competing financial interests statement}

The authors declare that they have no competing interests.

\section{References}

[1] J.M. Anderson, A. Rodriguez, D.T. Chang, Foreign body reaction to biomaterials Semin. Immunol. 20 (2) (2008) 86-100.

[2] H. Kweon, S.G. Kim, J.Y. Choi, Inhibition of foreign body giant cell formation by 4- hexylresorcinol through suppression of diacylglycerol kinase delta gene expression, Biomaterials 35 (30) (2014) 8576-8584.

[3] P.M. Mountziaris, P.P. Spicer, F.K. Kasper, A.G. Mikos, Harnessing and modulating inflammation in strategies for bone regeneration, Tissue Eng. Part B Rev. 17 (6) (2011) 393-402.

[4] L. Claes, S. Recknagel, A. Ignatius, Fracture healing under healthy and inflammatory conditions, Nat. Rev. Rheumatol. 8 (3) (2012) 133-143.

[5] I. Konnecke, A. Serra, T. El Khassawna, C. Schlundt, H. Schell, A. Hauser, A. Ellinghaus, H.D. Volk, A. Radbruch, G.N. Duda, K. Schmidt-Bleek, T and B cells participate in bone repair by infiltrating the fracture callus in a two-wave fashion, Bone 64 (0) (2014) 155-165.

[6] K. Schmidt-Bleek, H. Schell, J. Lienau, N. Schulz, P. Hoff, M. Pfaff, G. Schmidt, C. Martin, C. Perka, F. Buttgereit, H.D. Volk, G. Duda, Initial immune reaction and angiogenesis in bone healing, J. Tissue Eng. Regen. Med. 8 (2) (2014) $120-130$.

[7] S.G. Santos, M. Lamghari, C.R. Almeida, M.I. Oliveira, N. Neves, A.C. Ribeiro, J.N. Barbosa, R. Barros, J. Maciel, M.C. Martins, R.M. Goncalves, M.A. Barbosa, Adsorbed fibrinogen leads to improved bone regeneration and correlates with differences in the systemic immune response, Acta Biomater. 9 (7) (2013) $7209-7217$.

[8] A.F. Drew, H. Liu, J.M. Davidson, C.C. Daugherty, J.L. Degen, Wound-healing defects in mice lacking fibrinogen, Blood 97 (12) (2001) 3691-3698.

[9] S.N. Rodrigues, I.C. Goncalves, M.C. Martins, M.A. Barbosa, B.D. Ratner, Fibrinogen adsorption, platelet adhesion and activation on mixed hydroxylmethyl-terminated self-assembled monolayers, Biomaterials 27 (31) (2006) 5357-5367.

[10] R.F. Doolittle, K.W.K. Watt, B.A. Cottrell, D.D. Strong, M. Riley, The amino acid sequence of the $\alpha$-chain of human fibrinogen, Nature 280 (5722) (1979) 464-468.

[11] B.J. Rybarczyk, S.O. Lawrence, P.J. Simpson-Haidaris, Matrix-fibrinogen enhances wound closure by increasing both cell proliferation and migration, 
Blood 102 (12) (2003) 4035-4043.

[12] V.K. Lishko, N.P. Podolnikova, V.P. Yakubenko, S. Yakovlev, L. Medved, S.P. Yadav, T.P. Ugarova, Multiple binding sites in fibrinogen for integrin alphaMbeta2 (Mac-1), J. Biol. Chem. 279 (43) (2004) 44897-44906.

[13] A. Sahni, C.W. Francis, Vascular endothelial growth factor binds to fibrinogen and fibrin and stimulates endothelial cell proliferation, Blood 96 (12) (2000) 3772-3778.

[14] S. Shiose, Y. Hata, Y. Noda, Y. Sassa, A. Takeda, H. Yoshikawa, K. Fujisawa, T. Kubota, T. Ishibashi, Fibrinogen stimulates in vitro angiogenesis by choroidal endothelial cells via autocrine VEGF, Graefes Arch. Clin. Exp. Ophthalmol. 242 (9) (2004) 777-783.

[15] H. Wang, L. Shan, H. Zeng, M. Sun, Y. Hua, Z. Cai, Is fibrin sealant effective and safe in total knee arthroplasty? A meta-analysis of randomized trials, J. Orthop. Surg. Res. 9 (2014) 36.

[16] B.S. Kim, J. Lee, Enhanced bone healing by improved fibrin-clot formation via fibrinogen adsorption on biphasic calcium phosphate granules, Clin. Ora Implants Res. 26 (10) (2015) 1203-1210.

[17] Y. Yamada, J.S. Boo, R. Ozawa, T. Nagasaka, Y. Okazaki, K. Hata, M. Ueda, Bone regeneration following injection of mesenchymal stem cells and fibrin glue with a biodegradable scaffold, J. Craniomaxillofac Surg. 31 (1) (2003) 27-33.

[18] E. Seebach, H. Freischmidt, J. Holschbach, J. Fellenberg, W. Richter, Mesenchymal stroma cells trigger early attraction of M1 macrophages and endothelial cells into fibrin hydrogels, stimulating long bone healing without longterm engraftment, Acta Biomater. 10 (11) (2014) 4730-4741.

[19] T. Ikeda, Y. Miyata, Y. Tsutani, K. Misumi, K. Arihiro, M. Okada, Fibrinogen/ thrombin-based collagen fleece (TachoComb(R)) promotes regeneration in pulmonary arterial injury, Eur. J. Cardiothorac. Surg. 41 (4) (2012) 926-932.

[20] K. Singh, H. Moyer, J.K. Williams, Z. Schwartz, B.D. Boyan, Fibrin glue: a scaffold for cellular-based therapy in a critical-sized defect, Ann. Plast. Surg. 66 (3) (2011) 301-305.

[21] J.K. Ryu, M.A. Petersen, S.G. Murray, K.M. Baeten, A. Meyer-Franke, J.P. Chan, E. Vagena, C. Bedard, M.R. Machado, P.E. Rios Coronado, T. Prod'homme I.F. Charo, H. Lassmann, J.L. Degen, S.S. Zamvil, K. Akassoglou, Blood coagulation protein fibrinogen promotes autoimmunity and demyelination via chemokine release and antigen presentation, Nat. Commun. 6 (2015) 8164.

[22] E. Peled, J. Boss, J. Bejar, C. Zinman, D. Seliktar, A novel poly(ethylene glycol)fibrinogen hydrogel for tibial segmental defect repair in a rat model, J. Biomed. Mater. Res. A 80 (4) (2007) 874-884.

[23] C.R. Almeida, D.P. Vasconcelos, R.M. Goncalves, M.A. Barbosa, Enhanced mesenchymal stromal cell recruitment via natural killer cells by incorporation of inflammatory signals in biomaterials, J. R. Soc. Interface 9 (67) (2012) $261-271$.

[24] J. Maciel, M.I. Oliveira, E. Colton, A.K. McNally, C. Oliveira, J.M. Anderson, M.A. Barbosa, Adsorbed fibrinogen enhances production of bone- and angiogenic-related factors by monocytes/macrophages, Tissue Eng. Part A 20 $(1-2)(2014)$ 250-263.

[25] A.L. Torres, S.G. Santos, M.I. Oliveira, M.A. Barbosa, Fibrinogen promotes resorption of chitosan by human osteoclasts, Acta Biomater. 9 (5) (2013) 6553-6562.

[26] L. Le Guehennec, E. Goyenvalle, E. Aguado, M. Houchmand-Cuny, B. Enkel P. Pilet, G. Daculsi, P. Layrolle, Small-animal models for testing macroporous ceramic bone substitutes, J. Biomed. Mater. Res. B Appl. Biomater. 72 (1) (2005) 69-78.

[27] S. Mori, T. Sawai, T. Teshima, M. Kyogoku, A new decalcifying technique for immunohistochemical studies of calcified tissue, especially applicable to cell surface marker demonstration, J. Histochem. Cytochem. 36 (1) (1988) $111-114$

[28] I.W. McLean, P.K. Nakane, Periodate-lysine-paraformaldehyde fixative. A new fixation for immunoelectron microscopy, J. Histochem. Cytochem. 22 (12) (1974) 1077-1083.

[29] D.W. Dempster, J.E. Compston, M.K. Drezner, F.H. Glorieux, J.A. Kanis, $\mathrm{H}$. Malluche, PJ Meunier, S.M. Ott, R.R Recker, A.M. Parfitt, Standardized nomenclature, symbols, and units for bone histomorphometry: a 2012 update of the report of the ASBMR Histomorphometry Nomenclature Committee, J. Bone Miner. Res. 28 (1) (2013) 2-17.

[30] S.Y. Lin, Y.S. Wei, T.F. Hsieh, M.J. Li, Pressure dependence of human fibrinogen correlated to the conformational alpha-helix to beta-sheet transition: an Fourier transform infrared study microspectroscopic study, Biopolymers 75 (5) (2004) 393-402.

[31] R.I. Litvinov, D.A. Faizullin, Y.F. Zuev, J.W. Weisel, The alpha-helix to betasheet transition in stretched and compressed hydrated fibrin clots, Biophys. J. 103 (5) (2012) 1020-1027.

[32] R.I. Thacker, G.S. Retzinger, Adsorbed fibrinogen regulates the behavior of human dendritic cells in a CD18-dependent manner, Exp. Mol. Pathol. 84 (2) (2008) 122-130.

[33] D. Gibbings, A.D. Befus, CD4 and CD8: an inside-out coreceptor model for innate immune cells, J. Leukoc. Biol. 86 (2) (2009) 251-259.

[34] Q. Lv, Q. Feng, Preparation of 3-D regenerated fibroin scaffolds with freeze drying method and freeze drying/foaming technique, J. Mater. Sci. Mater. Med. 17 (12) (2006) 1349-1356.

[35] B.S. Kim, H.M. Sung, H.K. You, J. Lee, Effects of fibrinogen concentration on fibrin glue and bone powder scaffolds in bone regeneration, J. Biosci. Bioeng. 118 (4) (2014) 469-475.

[36] P.J. Johnson, S.R. Parker, S.E. Sakiyama-Elbert, Fibrin-based tissue engineering scaffolds enhance neural fiber sprouting and delay the accumulation of reactive astrocytes at the lesion in a subacute model of spinal cord injury, J. Biomed. Mater. Res. A 92 (1) (2010) 152-163.

[37] M.P. Linnes, B.D. Ratner, C.M. Giachelli, A fibrinogen-based precision microporous scaffold for tissue engineering, Biomaterials 28 (35) (2007) $5298-5306$.

[38] T. Osathanon, M.L. Linnes, R.M. Rajachar, B.D. Ratner M.J. Somerman, C.M. Giachelli, Microporous nanofibrous fibrin-based scaffolds for bone tissue engineering, Biomaterials 29 (30) (2008) 4091-4099.

[39] W.K. Lew, F.A. Weaver, Clinical use of topical thrombin as a surgical hemostat, Biologics 2 (4) (2008) 593-599.

[40] K. Griebenow, A.M. Klibanov, Lyophilization-induced reversible changes in the secondary structure of proteins, Proc. Natl. Acad. Sci. U. S. A. 92 (24) (1995) 10969-10976.

[41] H.C.F. Cote, K.P. Pratt, E.W. Davie, D.W. Chung, The polymerization pocket 'a' within the carboxyl-terminal region of the gamma chain of human fibrinogen is adjacent to but independent from the calcium-binding site, J. Biol. Chem. 272 (38) (1997) 23792-23798.

[42] K. Suehiro, J. Mizuguchi, K. Nishiyama, S. Iwanaga, D.H. Farrell, S. Ohtaki, Fibrinogen binds to integrin alpha(5)beta(1) via the carboxyl-terminal RGD site of the Aalpha-chain, J. Biochem. 128 (4) (2000) 705-710.

[43] V. Karageorgiou, D. Kaplan, Porosity of 3D biomaterial scaffolds and osteogenesis, Biomaterials 26 (27) (2005) 5474-5491.

[44] F. Haverkate, G. Timan, Protective effect of calcium in the plasmin degradation of fibrinogen and fibrin fragments D, Thromb. Res. 10 (6) (1977) 803-812.

[45] K.A. Alexander, M.K. Chang, E.R. Maylin, T. Kohler, R. Muller, A.C. Wu, N. Van Rooijen, M.J. Sweet, D.A. Hume, L.J. Raggatt, A.R. Pettit, Osteal macrophages promote in vivo intramembranous bone healing in a mouse tibial injury model, J. Bone Miner. Res. 26 (7) (2011) 1517-1532.

[46] A.E. Vieira, C.E. Repeke, B. Ferreira Junior Sde, P.M. Colavite, C.C. Biguetti, R.C. Oliveira, G.F. Assis, R. Taga, A.P. Trombone, G.P. Garlet, Intramembranous bone healing process subsequent to tooth extraction in mice: microcomputed tomography, histomorphometric and molecular characterization, PLoS One 10 (5) (2015) e0128021.

[47] A.J. Gray, J.E. Bishop, J.T. Reeves, G.J. Laurent, A alpha and B beta chains of fibrinogen stimulate proliferation of human fibroblasts, J. Cell Sci. 104 (Pt 2) (1993) 409-413.

[48] L. Micallef, N. Vedrenne, F. Billet, B. Coulomb, I.A. Darby, A. Desmouliere, The myofibroblast, multiple origins for major roles in normal and pathological tissue repair, Fibrogenes. Tissue Repair 5 (Suppl. 1) (2012) S5.

[49] F. Shapiro, Bone development and its relation to fracture repair. The role of mesenchymal osteoblasts and surface osteoblasts, Eur. Cell Mater. 15 (2008) $53-76$.

[50] J. Lorenz, E. Seebach, G. Hackmayer, C. Greth, R.J. Bauer, K. Kleinschmidt, D. Bettenworth, M. Bohm, J. Grifka, S. Grassel, Melanocortin 1 receptorsignaling deficiency results in an articular cartilage phenotype and accelerates pathogenesis of surgically induced murine osteoarthritis, PLoS One 9 (9) (2014) e105858.

[51] M. Frohbergh, Y. Ge, F. Meng, N. Karabul, A. Solyom, A. Lai, J. Iatridis, E.H. Schuchman, C.M. Simonaro, Dose responsive effects of subcutaneous pentosan polysulfate injection in mucopolysaccharidosis type VI rats and comparison to oral treatment, PLoS One 9 (6) (2014) e100882.

[52] S.J. Roberts, N. van Gastel, G. Carmeliet, F.P. Luyten, Uncovering the periosteum for skeletal regeneration: the stem cell that lies beneath, Bone 70 (2015) $10-18$.

[53] P.H. Bullens, H.W. Schreuder, M.C. de Waal Malefijt, N. Verdonschot, P. Buma, The presence of periosteum is essential for the healing of large diaphyseal segmental bone defects reconstructed with trabecular metal: a study in the femur of goats, J. Biomed. Mater. Res. B Appl. Biomater. 92 (1) (2010) 24-31.

[54] B.S. Kim, H.J. Kim, J.G. Choi, H.K. You, J. Lee, The effects of fibrinogen concentration on fibrin/atelocollagen composite gel: an in vitro and in vivo study in rabbit calvarial bone defect, Clin. Oral Implants Res. 26 (11) (2015) 1302-1308.

[55] X. Yang, B.F. Ricciardi, A. Hernandez-Soria, Y. Shi, N. Pleshko Camacho, M.P. Bostrom, Callus mineralization and maturation are delayed during fracture healing in interleukin-6 knockout mice, Bone 41 (6) (2007) 928-936.

[56] M. Perl, F. Gebhard, M.W. Knoferl, M. Bachem, H.J. Gross, L. Kinzl, W. Strecker, The pattern of preformed cytokines in tissues frequently affected by blunt trauma, Shock 19 (4) (2003) 299-304.

[57] P.M. Mountziaris, A.G. Mikos, Modulation of the inflammatory response for enhanced bone tissue regeneration, Tissue Eng. Part B Rev. 14 (2) (2008) $179-186$.

[58] Y. Tang, X. Wu, W. Lei, L. Pang, C. Wan, Z. Shi, L. Zhao, T.R. Nagy, X. Peng, J. Hu, X. Feng, W. Van Hul, M. Wan, X. Cao, TGF-beta1-induced migration of bone mesenchymal stem cells couples bone resorption with formation, Nat. Med. 15 (7) (2009) 757-765.

[59] Y.Y. Wan, R.A. Flavell, 'Yin-Yang' functions of transforming growth factor-beta and $\mathrm{T}$ regulatory cells in immune regulation, Immunol. Rev. 220 (2007) 199-213.

[60] Y. Gao, W.P. Oian, K. Dark, G. Toraldo, A.S. Lin, R.E. Guldberg, R.A. Flavell, M.N. Weitzmann, R. Pacifici, Estrogen prevents bone loss through transforming growth factor beta signaling in T cells, Proc. Natl. Acad. Sci. U. S. A. 101 (47) (2004) 16618-16623.

[61] M.J. Gros, P. Naquet, R.R. Guinamard, Cell intrinsic TGF-beta 1 regulation of $B$ cells, J. Immunol. 180 (12) (2008) 8153-8158.

[62] S. Wahl, D. Hunt, L. Wakefield, N. McCartney-Francis, L. Wahl, A. Roberts, 
M. Sporn, Transforming growth factor type beta induces monocyte chemotaxis and growth factor production, Proc. Natl. Acad. Sci. U. S. A. 84 (16) (1987) $5788-5792$.

[63] J.S. Kim, J.G. Kim, M.Y. Moon, C.Y. Jeon, H.Y. Won, H.J. Kim, Y.J. Jeon, J.Y. Seo, J.I. Kim, J. Kim, J.Y. Lee, P.H. Kim, J.B. Park, Transforming growth factor-beta1 regulates macrophage migration via RhoA, Blood 108 (6) (2006) 1821-1829.

[64] R. Chung, J.C. Cool, M.A. Scherer, B.K. Foster, C.J. Xian, Roles of neutrophilmediated inflammatory response in the bony repair of injured growth plate cartilage in young rats, J. Leukoc. Biol. 80 (6) (2006) 1272-1280.

[65] S. Scaglione, M. Cilli, M. Fiorini, R. Quarto, G. Pennesi, Differences in chemical composition and internal structure influence systemic host response to implants of biomaterials, Int. J. Artif. Organs 34 (5) (2011) 422-431.

[66] C. Schlundt, H. Schell, S.B. Goodman, G. Vunjak-Novakovic, G.N. Duda, K. Schmidt-Bleek, Immune modulation as a therapeutic strategy in bone regeneration, J. Exp. Orthop. 2 (1) (2015) 1.

[67] S, Reinke, S Geissler, WR Taylor K Schmidt-Bleek, K Juelke, V. Schwachmeyer, M. Dahne, T. Hartwig, L. Akyuz, C. Meisel, N. Unterwalder, N.B. Singh, P. Reinke, N.P. Haas, H.D. Volk, G.N. Duda, Terminally differentiated CD8(+) T cells negatively affect bone regeneration in humans, Sci. Transl.
Med. 5 (177) (2013) 177ra36.

[68] K. Sadtler, K. Estrellas, B.W. Allen, M.T. Wolf, H. Fan, A.J. Tam, C.H. Patel, B.S. Luber, H. Wang, K.R. Wagner, J.D. Powell, F. Housseau, D.M. Pardoll J.H. Elisseeff, Developing a pro-regenerative biomaterial scaffold microenvironment requires T helper 2 cells, Science 352 (6283) (2016) 366-370.

[69] B. Rubin, C. Matron, The mouse immune response to human fibrinogen reveals an autoimmune component against mouse fibrinogen, Cell Immunol 233 (1) (2005) 41-52.

[70] D.M. Fowlkes, N.T. Mullis, C.M. Comeau, G.R. Crabtree, Potential basis for regulation of the coordinately expressed fibrinogen genes: homology in the $5^{\prime}$ flanking regions, Proc. Natl. Acad. Sci. U. S. A. 81 (8) (1984) 2313-2316.

171] A. Scriba, V. Grau, B. Steiniger, Phenotype of rat monocytes during acute kidney allograft rejection: increased expression of NKR-P1 and reduction of CD43, Scand. J. Immunol. 47 (4) (1998) 332-342.

[72] V. Grau, O. Stehling, H. Garn, B. Steiniger, Accumulating monocytes in the vasculature of rat renal allografts: phenotype, cytokine, inducible NO synthase, and tissue factor mRNA expression, Transplantation 71 (1) (2001) $37-46$. 